\title{
Vislumbrando intimidades: narrativas espaciales en tránsito
}

\author{
Eduardo Álvarez Pedrosian \\ (Universidad de São Paulo, DA-FFLCH-USP, Brasil)
}

Recibido: $28 / 3 / 2015$

Aceptado: 22/6/2015

Resumen. En este artículo nos centramos en el estudio de los espacios de la intimidad, intentando poner en juego esta dimensión muchas veces dejada de lado en los estudios sobre comunicación y ciudad. Nuestro análisis se inscribe en una investigación etnográfica más amplia, en relación a las transformaciones en el hábitat y las formas de habitar a partir de las acciones de un plan socio-habitacional estatal en Uruguay. En primer lugar, proponemos un desplazamiento conceptual desde la noción de lo privado a la de lo íntimo. En segundo término, tratamos las estrategias y tácticas de abordaje de la intimidad surgidas en nuestro trabajo de campo. Posteriormente, nos sumergimos en dos casos de estudio que permiten tratar las cuestiones centrales al respecto.

PALABRAS clave: intimidad / narrativas / espacialidad / comunicación / plan habitacional

\section{Glimpsing Intimacies: Spatial Narratives in Transit}

SumMARY. In this paper we focus in studying intimate spaces, aiming at putting into play this dimension often times set aside by communication and studies of cities. Our analysis is part of a wider research of ethnographic nature about the transformation of the habitat and ways of dwelling, parting from the actions of a social housing plan in Uruguay. First, we propose a conceptual shift from the notion of the private to the intimate. Second, we address the strategies and tactics of the intimacy approach that emerged from our fieldwork. Later, we dive into two case studies that allow addressing our central questions.

Key words: intimacy / narratives / spatiality / communication / housing plan 


\section{A modo de contextualización}

$\mathrm{E}$ ste artículo es fruto de una investigación de mayor alcance, en el contexto del llamado Plan socio-habitacional Juntos, creado por ley en 2011, a partir de las inquietudes y financiación directa del presidente José "Pepe" Mujica en su mandato como presidente de Uruguay (2010-2015) (Poder Legislativo de la ROU, 2011). El hecho de focalizar nuestra investigación de corte etnográfico en tal marco, responde a la necesidad de contribuir con la producción de conocimiento en dicho emprendimiento, sobre la premisa de la necesidad también de poner en juego la dimensión mediacional de producción de subjetividad asociada al hábitat y las formas de habitar en tales circunstancias, como aporte para pensar y conocer otras realidades.

Por lo general, las investigaciones en comunicación y ciudad tienen por objeto el estudio de los llamados "espacios públicos", de acceso más o menos directo por parte del investigador. En esta oportunidad planteamos la necesidad de complementar dicha situación, poniendo de manifiesto la relevancia del análisis de las espacialidades de la intimidad y sus temporalidades asociadas. Accedimos, por tanto, a una serie de narrativas discursivas referidas a sus espacios asociados. Estas se encuentran en tránsito en un doble sentido: por tratarse de un contexto de transformación gracias a la intervención del Plan, y de ser producidas en instancias de investigación, que impli- caron desplazamientos espaciales en conjunto con los habitantes, quienes nos dieron acceso a sus intimidades de esa forma, lo cual, como veremos, tiene implicancias epistemológicometodológicas y éticas precisas.

\section{De lo privado a lo íntimo}

Como hemos planteado en otra ocasión, resulta necesario insistir en la necesidad de pensar y conocer más allá de dualismos como los de público/ privado (Álvarez, 2014b). Igualmente, sigue existiendo una distinción no solo analítica, sino más bien surgida del campo de experiencias objeto de esta etnografía. También es una problemática propia de los desafíos contemporáneos en torno a la producción de subjetividad, y en especial en aquellos estudios focalizados en diversas tendencias de investigación en ciudad, comunicación y espacialidades, en el gran estuario de perspectivas llamado estudios culturales urbanos (García y Román, 2011; Chaves, 2013; Álvarez, 2014a).

En dicha oportunidad, hemos intentado plantear la discusión al respecto a partir del esfuerzo por desustancializar la noción de "espacio público", considerando en primer término la descomposición de la asociación entre los términos, tomada como punto de partida, cuando de hecho, se trata de uno de llegada. La conjunción también esconde la pluralidad. Es así que nos planteamos la existencia de "espacios 
y públicos" heterogéneos, a veces ligados a "territorios de lo público" específicos (Álvarez, Del Castillo, Lamoglie, 2014), donde podemos finalmente encontrar las problemáticas clásicas de la "antropología de las calles" sin caer nuevamente en oposiciones clásicas (Delgado, 2007). Esto no menosprecia el poder que tuvo y sigue teniendo el diseño individualista de lo humano desde la planificación y las prácticas de las instituciones modernas y contemporáneas de tipo occidental, en especial las enfrascadas en dispositivos de poder al estilo de las "sociedades de control" tematizadas por Deleuze, como paso siguiente de las disciplinarias estudiadas a su vez por Foucault, donde el individuo deviene "dividual" y las masas "indicadores, datos, mercado o bancos" (Deleuze, 1995, pp. 281-282).

En el mismo sentido, planteamos ahora la necesidad de pasar de pensar en términos de "lo privado" a lo "íntimo". De esta forma nos encontramos con este tipo de paradojas a las que es necesario enfrentar para comprender estos fenómenos aquí estudiados: el hecho de que cuanto más en la intimidad nos encontremos, más aparecen visibles los componentes sociales, colectivos, inter y transsubjetivos. O sea: que cuanto más adentro nos internemos más en el afuera estaremos (Álvarez, 2011a). Esto no le quita valor a la singularidad, más bien todo lo contrario; de cierto modo, es la vuelta a la máxima ontológica aristotélica de que "el ser se dice de muchas maneras", pero sin dejar de problematizar di- cha entidad para nada sustancial, sino siempre circunstancial: "anclada en finitud del ser-ahí" diría Guattari (2000, p. 18), intentando absorber y superar al propio Heidegger y otras fenomenologías de corte existencial.

Cuando Geertz (1996, p. 58) plantea que la cultura se caracteriza por particularizar a todo nivel y escala apuntaba a lo mismo; de igual manera Castoriadis, aunque en otros términos (1997, p. 136): lo más universal de lo humano es su singularización, propia de toda práctica, que encuentra su trasfondo en la creatividad. Más recientemente, Herzfeld (2004) ha elaborado su teoría antropológica sobre una base semejante: la "intimidad cultural" se presenta como dimensión de la sensibilidad y creatividad más prosaica, donde se generan "esencializaciones" gracias a las cuales se lleva a cabo la producción de subjetividad, sin necesidad de que las formas institucionales sean experimentadas solamente como ajenas y de forma coercitiva, sino más bien todo lo contrario. Este es, para el autor, el caso emblemático de los nacionalismos. No por casualidad: "La casa, como una forma de esencialización de las relaciones de parentesco en términos de residencia, es un lugar para la transmisión de la substancia de la identidad cultural" (Bestard, 2006, p. 59). También nos encontramos con esta tendencia en la historia de la sensibilidad, "de la vida privada" como se la denominó, con sus análisis enfocados de la misma forma en los procesos de subjetivación, siendo el caso más extremo de la 
intimidad el relativo a la sexualidad, y encontrando en el espacio de la alcoba una excelente oportunidad para el planteo de una arqueología del habitar occidental (Perrot, 2011).

¿Hay algún vestigio de la noción de lo privado que debamos rescatar a pesar del desplazamiento conceptual y perceptible hacia la intimidad? Ciertamente, la cuestión del apartarse de los demás, de los otros, a su potencial visibilidad y captación en un sentido comunicacional, sean las mediaciones que sean, hacen a los límites y definiciones de lo íntimo. Delgado (2007, pp. 30-31) lo asocia a la necesidad etológica de todo animal de resguardarse, que es la base de la conformación de múltiples variaciones antropológicas. Podemos plantearnos si existe algún umbral al respecto, alguna configuración para la cual no exista esta necesidad. Las espacialidades de quienes habitan en las calles de los centros urbanos, los "sin-techo", homeless o como se los defina, también presentan alguna forma de retraimiento y cobijo, un "aire de intimidad" ante los flujos de información y comunicación propios de los territorios públicos (Desjarlais, 1997, p. 80), de la dimensión del "otro generalizado", tal como fue definida por Herbert Mead (Delgado, 1999, p. 14). Y lo mismo en otro sentido, cuando ciertas subjetividades son enfrentadas a un cambio radical del entorno doméstico aparentemente de mejor calidad, pero que aterroriza y horroriza por ser en principio imposible su delimitación, su dimensionalidad, se- gún formas y funciones de un habitar puesto en riesgo (Jacobs, 2004).

Se trata, por tanto, de una suerte de distensión, de relajamiento de las actitudes, de un "agenciamiento" (Deleuze y Guattari, 1997) en el cual los sujetos pueden liberarse de la necesidad de sostener una presencia según "máscaras" en situaciones y escenarios de mayor tensión (Goffman, 2004). El "hogar" no es exactamente lo mismo, ya que como lo ha planteado Heidegger (1994) en su análisis de la noción del habitar en función al cuidado y la preservación, también puede experimentarse en relación a un territorio más vasto que el exclusivo y excluyente, o sea el íntimo. Sin embargo, es igual de cierto que se hace necesaria una conexión singularizante con este ámbito cargado de afectos y sentimientos por parte del sujeto, como para que sea experimentado como tal, donde uno "se siente en casa" (Heller, 1995). De allí la milenaria asociación del hogar con el fogón, y de este con la seguridad de lo familiar (Segalen, 1996), a partir en definitiva de la condición según la cual se puede comer y dormir sin ser aniquilado de imprevisto, o sea, de poder refugiarse (Pezeu-Massabuau, 1988).

Como planteábamos, esto no quita que frente a la soledad del espejo dentro de una vivienda, uno no siga cargando con todas las configuraciones inter y transsubjetivas que lo definen como miembro de una sociedad y hasta de una especie, en medio de otras entidades, como animales domésticos 
y objetos de variada índole. Pero lo cierto es que puede darse este apartamiento de las presiones frente a las miradas de los demás, tanto aquellos más conocidos por una cotidianidad compartida como otros potencialmente desconocidos. Allí radica el núcleo de la intimidad, lo que puede asociarse directamente a los límites del espacio interior de una vivienda, pero que no se reduce solo a ello, ya que este agenciamiento puede estar dispuesto en diferentes escalas y modalidades, tanto hacia ese interior (por ejemplo, en una sola habitación) como al exterior (en jardines traseros, o en toda una calle o senda). Su definición es una cuestión mediacional, dependiendo del tipo de sentidos puestos en juego y las semiosferas que allí operan culturalmente, con la peculiaridad de tratarse de una "doble vida semiótica", donde se modeliza el universo y se es modelizado por este (Lotman, 2000, p. 103).

Nuestra investigación -centrada en las transformaciones en las formas de habitar en quienes son partícipes de una intervención "sociohabitacional", como se autodenominó el Plan Juntos en el contexto del gobierno de Mujica en Uruguay- es una excelente oportunidad para comprender estas cuestiones, dados los contextos de procedencia y las prácticas desencadenadas una vez que se hace posible proyectar y dar cabida a otra existencia. ¿Qué ocurre con la dinámica de esencialización, al parecer tan poderosa en el ámbito de la intimidad (Herzfeld, 2004), cuando esta se encuentra en diferentes fases de gestación y consolidación? Puede tratarse tanto de un extremo como del otro, y de todas las combinaciones intermedias, según variables de procedencia en las formas de habitar de los protagonistas de estos cambios, así como de los entornos públicos que también se encuentran en diferentes momentos de formación y según ciertas maneras de darse, a partir de una coexistencia con otros que son, en la mayoría de los casos, desconocidos hasta el momento. El "jardín interior", el "templo" de cada uno y sus seres más cercanos, puede ser el refugio por excelencia, así como abrirse a otras experiencias más o menos compartidas, más allá de los vínculos primarios del grupo o red doméstica cotidiana tomada de base para la conformación de la vivienda, según fuerzas instituyentes como las de los dispositivos de intervención de este plan.

\section{Estrategias y tácticas de abordaje de la intimidad: estancias y paseos en compañía}

Porque la casa es nuestro rincón del mundo. Es -se ha dicho con frecuencia-nuestro primer universo. Es realmente un cosmos. Un cosmos en toda la acepción del término. Vista intimamente, la vivienda más humilde ¿no es la más bella? Los escritores de la "habitación humilde" evocan a menudo ese elemento de la poética del espacio. Pero dicha evocación peca de sucinta. Como tienen poco que describir en la humilde vivienda, no permanecen mucho en ella. 
Caracterizan la habitación humilde en su actualidad, sin vivir realmente su calidad primitiva, calidad que pertenece a todos, ricos o pobres, si aceptan soñar.

Gastón Bachelard (2000, p. 28).

Imposible acceder a esta dimensión de fenómenos espacio-temporales de las mediaciones productoras de subjetividad sin contar, a su vez, con cierta mediación. Esto es un rasgo común a toda investigación en estos campos de estudio, pero en esta cuestión se convierte en un tema relevante. La ilusión de que es posible conocer directamente, en forma transparente, sin mediación, lo que ocurre en la intimidad de la vida de los seres humanos vuelve cada cierto período con frecuencia, cuando lo interesante y estimulante es todo lo contrario: explorar formas de crear colaborativamente un conocimiento sobre estas dimensiones constitutivas de lo que somos en forma dialógica y constructiva.

En tal sentido, es posible aplicar diferentes técnicas a partir de una metodología de tipo etnográfica. Su elección depende de las características en las que se realiza la investigaciónintervención de la que se trate. En nuestro caso, pudimos participar investigando estos fenómenos junto a los habitantes de dos emplazamientos donde actúa el Plan Juntos, gracias a la apertura de sus respectivos equipos de base, conformados por arquitectos y técnicos sociales, en especial por los llamados educadores y trabajadores sociales, en un clima de mucho cuida- do ante la presencia de cualquier agente externo, como es el caso de este etnógrafo, llegado del campo académico.

La posibilidad de realizar observaciones participantes en los territorios de la intimidad encierra una dificultad siempre presente: si se trata de un entorno explícitamente apartado de la presencia de los otros, vedado y velado con tal fin, no se podrá acceder a él sino es, podríamos decir, bajo tutoría, como invitado al que se le ha hecho, en el mejor de los casos, una concesión gracias a una confianza que hay que ganársela. Cuestión particular que pone en juego un tema general en su radicalidad epistemológica. Como en todo esfuerzo etnográfico, la autenticidad debe buscarse en este tipo de vínculos dialógicos de involucramiento intenso, no en seudocientificismos que apelen a verdades desnudas con la utilización de presuntas máquinas objetivas, al estilo de los reality shows contemporáneos, es decir, de un "simulacro" (Baudrillard, 1993) que no se reconoce como tal: en este caso, queriendo poner cámaras ocultas en los hogares o disparates de ese tipo. Por el contrario, aceptamos el carácter "hiper-real" de la creación de conocimiento sobre los fenómenos humanos de existencia, de "ficciones persuasivas" con la que trabajar etnográficamente, "dando vida" a "escenas" e "ideas" (Strathern, 1991, p. 226), a partir de la experiencia del extrañamiento que opera en la tensión entre el distanciamiento y la inmersión en tanto forma de objetivación reflexiva y crítica consigo misma (Álvarez, 2011c). 
A continuación presentamos una serie de consideraciones a partir de dos experiencias de campo seleccionadas, que consistieron en la realización de entrevistas en profundidad en los ambientes íntimos de algunos de los participantes del Plan, instancias que terminaron convirtiéndose también en productoras de conocimiento sobre dichos espacios, bajo la doble condición complementaria de ser entrevistas de recorridas y recorridas entrevistadas. Luego de procesar los materiales de campo reflexivamente, nos percatamos de este hecho, lo que técnica y metodológicamente implica cuestiones teóricas sobre las problemáticas aquí abordadas (Álvarez, 2008): la espacialidad y las formas de habitarla poseen también una doble condición, la propia del "serahi'" (Dasein) en tanto estar y transitar (Heidegger, 1994), punto y trayecto al mismo tiempo de un "estriaje" y "alisamiento" simultáneos (Deleuze y Guattari, 1997, pp. 483-509).

Fue así como pudimos alcanzar a vislumbrar algo sobre estas intimidades, gracias a la confianza generada, la participación explícita de los sujetos involucrados en los fenómenos de estudio, en experiencias compartidas que son estares en tránsito (Álvarez, 2011b). De allí surgen narrativas, devenires que surcan el tiempo y el espacio dentro de un universo existencial imposible de reconstruir por fuera de estas líneas y redes: contando relatos, tejiendo, caminando, cantando, dibujando, escribiendo, etcétera (Ingold, 2007). Desde el campo de la arquitectura y el diseño se apela a este tipo de técnicas para aquellos prestigiosos profesionales que construyen sus propias viviendas y las exhiben de esta forma, en el mejor de los casos en un esfuerzo por objetivarlas para el conocimiento de sí mismos y de los otros, y en el peor en la banalidad de las revistas de modas. En la primera de las acepciones, nos encontramos con un gesto similar, pero en vez de tratarse de arquitectos y diseñadores socialmente sancionados como tales en un campo determinado, se trata de habitantes corrientes, sujetos que nos muestran por un momento su vida íntima, sus diseños artesanales, las huellas de sus habitares.

\section{El ensueño poético tras años en la intemperie}

María y Pérez ${ }^{1}$ habitaban desde hacía años en una pequeña vivienda próxima a cumplir un siglo de construida, la cual se encontraba en condiciones muy precarias, y que había sido el típico resguardo para el cuidador de un predio rural y su familia. En una zona semirrural del departamento de Montevideo, conocida por algunos como Cerro Oeste, el acceso a los bienes y servicios culturales es bastante limitado. Llega-

1 Todos los nombres han sido alterados para mantener el anonimato. 
ron al Plan Juntos a partir de la crisis habitacional por el estado de su vivienda, tanto edilicio como judicial, pues el predio donde está emplazada es una propiedad en venta, muy apetecible para la nueva oleada de capitales transnacionales interesados en instalaciones fabriles o de acopio de mercaderías, lo que está transformando drásticamente el paisaje circundante.

Vivían allí junto a su pequeño hijo varón de edad escolar, un adolescente, la madre de María, y por momentos con una hija también adolescente fruto de una relación pasada, la cual a su vez era madre de una pequeña criatura. Como hemos señalado en otra parte (Álvarez, 2014b), diferentes estrategias de diseño del entorno intentaron generar un límite manejable ante una suerte de inmensidad que los desbordaba ampliamente, en especial marcando una traza a un lado del perímetro de la pequeña casa con un sendero o camino doméstico, el cual también les sirvió para intentar negociar una posible compra, que no tuvo éxito frente a las grandes demandas, aunque aún no se hayan concretado. Tuve la gran oportunidad de sostener una extensa entrevista en profundidad con la pareja en lo que vendría a ser el estar de su hogar, casi medio año antes de que lo dejaran finalmente para mudarse a la nueva vivienda que fueron construyendo junto a otros en el marco del Plan, en el llamado "Barrio Amanecer", a unos tres o cuatro kilómetros hacia el centro de la mancha urbana, sin dejar de estar en la zona oeste del departamento capitalino.

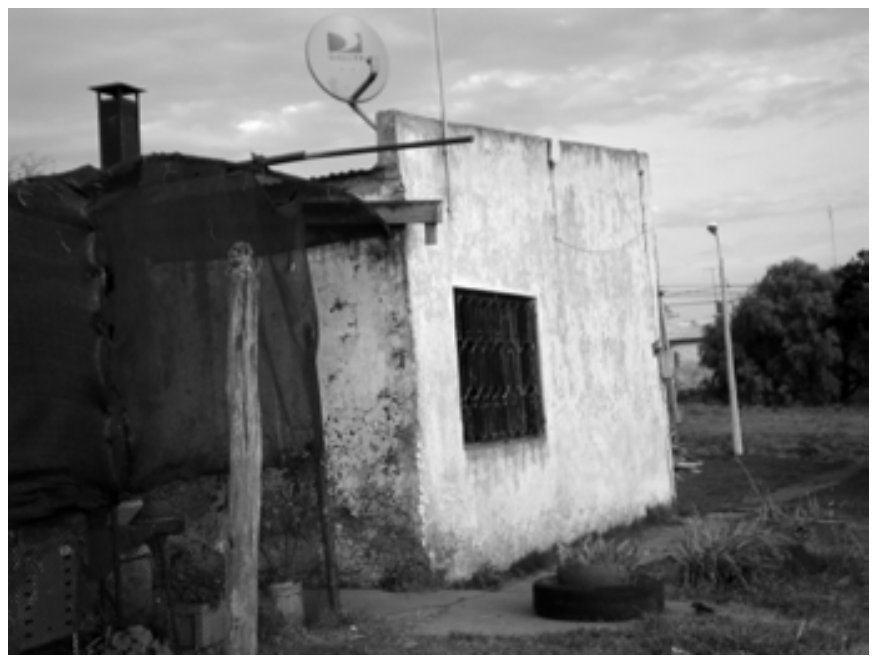

1. Antigua vivienda de María y Pérez, en la zona rural de Montevideo².

2 Todas las fotografías son del autor del artículo. 
Antes y después de instalarnos allí, me invitaron a recorrer juntos el predio, así como algunos de los espacios interiores menos íntimos de todos: la cocina ya era visible por estar integrada al estar, el baño, un cuarto que oficiaba de cambiador de ropa y depósito, y una habitación que había sido erigida como gimnasio de entrenamiento para su hijo adoptivo adolescente; lo único finalmente vedado para el etnógrafo eran los dos dormitorios.

La imagen anterior y las dos siguientes corresponden a dicho entorno inmediato; la primera es la que mira hacia el camino que conecta con la trama territorial, y donde puede observarse el espacio de estar de la vivienda desde el exterior en su fachada oeste. La segunda mira hacia el norte, que corresponde con el interior del gran predio donde se inserta la vivienda, y los límites de este con otros, donde ya se levantaron grandes galpones. Estos "aparecieron de la nada, y en tres meses los tenés ahí", al decir de Pérez. La tercera fotografía se orienta hacia el oeste, a donde da la ventana de esta fachada considerada como la principal. Enseguida nos entra la duda de cuál es el frente y cuál el fondo, cómo se orientan estos habitantes en este territorio.

Efectivamente, sobre lo que parece la fachada principal, hacia el camino, se encontraba una pieza que oficiaba entonces de dormitorio, y tenía la puerta clausurada debido a su función y la necesidad de espacio por el haci- namiento. La entrada cotidiana a la vivienda se daba, como en tantas casas rurales, por el lado trasero, aquel de espaldas al ámbito de lo público, en este caso el camino por el que pasaba el transporte suburbano y los peatones del vecindario. La tercera imagen también es significativa en tanto constituye el paisaje enmarcado por la ventana principal de la vivienda, la del estar, que puede apreciarse en la primera fotografía. Esta imagen constituye para María principalmente el paradigma de su concepción del entorno, y está cargada de fuertes afectos sobre lo que identifica con su forma de habitar. Esto es, en definitiva, lo que más perdería una vez que se mudara y dejara esta vivienda precaria: los vastos horizontes rurales, asociados al aire limpio, los pájaros y la vegetación medio silvestre y medio colonizada por ella y los habitantes cercanos.

Las paredes exteriores de la casa originaria expresaban el paso del tiempo, el declinar de los materiales, lo que contrastaba fuertemente con los bloques de hormigón con los que levantaron las nuevas piezas adosadas. Cual cáscara totalmente horadada, daba casi por sentado lo que del otro lado, el interior, se podía llegar a encontrar, disolviendo las fronteras, en una suerte de membrana porosa a pesar de no llegar a divisarse lo que había más allá.

Una jaula artesanal encerraba un gallo dentro, y servía de pared un viejo cartel de chapa oxidado, donde se podía leer claramente la inscrip- 
ción "milanesas prontas para llevar, 2 x 20", en pesos uruguayos. Se trataba de restos de tácticas de sobrevivencia que desarrollaron durante la crisis económico-social centrada en el 2002 en la región, cuando la exclusión y los niveles de pobreza crónica ascendieron como nunca en el Uruguay, acercándolo a las demás realidades de la región y el continente, el más desigual del mundo. Como hemos investigado en otra ocasión en una de las zonas más emblemáticas de la periferia montevideana (Álvarez, 2013a), la elaboración de comida en el hogar fue aquí también una solución transitoria, que permitió al núcleo familiar sobrevivir. Pérez y María lo recordaban hasta con cariño, ante mis preguntas, delante del cartel convertido en parte de la jaula, lo que luego fue retomado en la entrevista extensa que tuvimos sentados en el estar, a propósito de las memorias de la resistencia oriundas de tales circunstancias: cómo se vendía esa carne picada hecha hamburguesa y rebozada en pan rallado y huevo que realizaban allí, o también con filetes de pescado que él conseguía de su trabajo en los frigoríficos cercanos.

Dentro de la vivienda, el espacio de estar es el corazón del hogar. Las tres imágenes siguientes dan cuenta del momento del encuentro y posterior salida de recorrida por el resto de los ámbitos interiores menos los dormitorios, y retorno al perímetro exterior. Podemos hacernos una idea de este tipo de paisaje en tanto "atmósfera y encarnación", y no tan solo horizonte visual

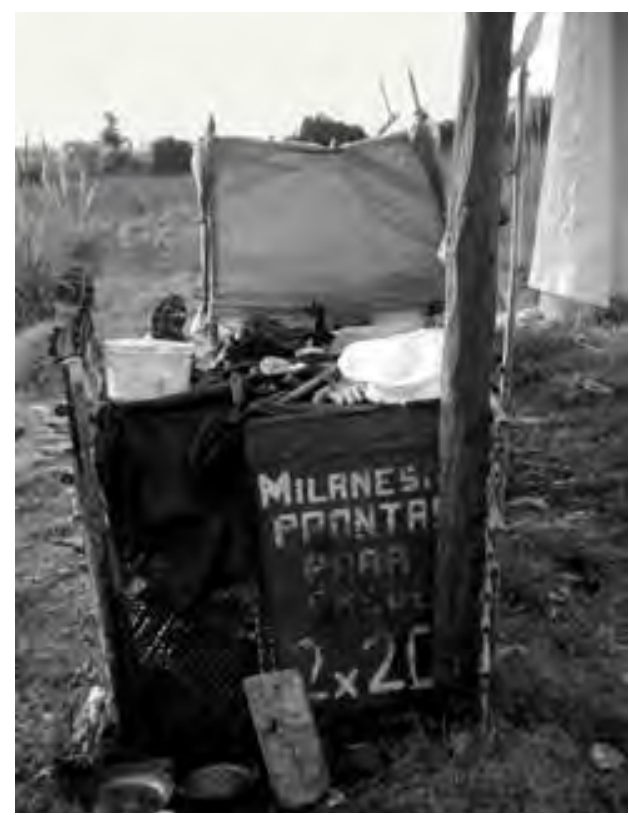

2. Jaula para el gallo hecha con materiales reutilizados.

(Jóhannesdóttir, 2010), que combina de forma interesante una ventana hacia el ocaso con la pantalla de televisión, en esos tiempos ocupada preferentemente con animaciones infantiles.

"Lloré muchísimo", me narraba María ya en su nueva casa, a lo que su pareja asentía con la cabeza y agregaba comentarios acerca de lo difícil que fue comprender que extrañara aquella vivienda tan precaria teniendo ahora la posibilidad de estrenar otra, hecha con sus propias manos. Pero es que, como también ellos mismos afirmaban, la composición particular del entorno exterior y el interior gracias a este tipo de dispositivos como la ventana del viejo estar, posee una cualidad difícil de igualar, a pesar de que 


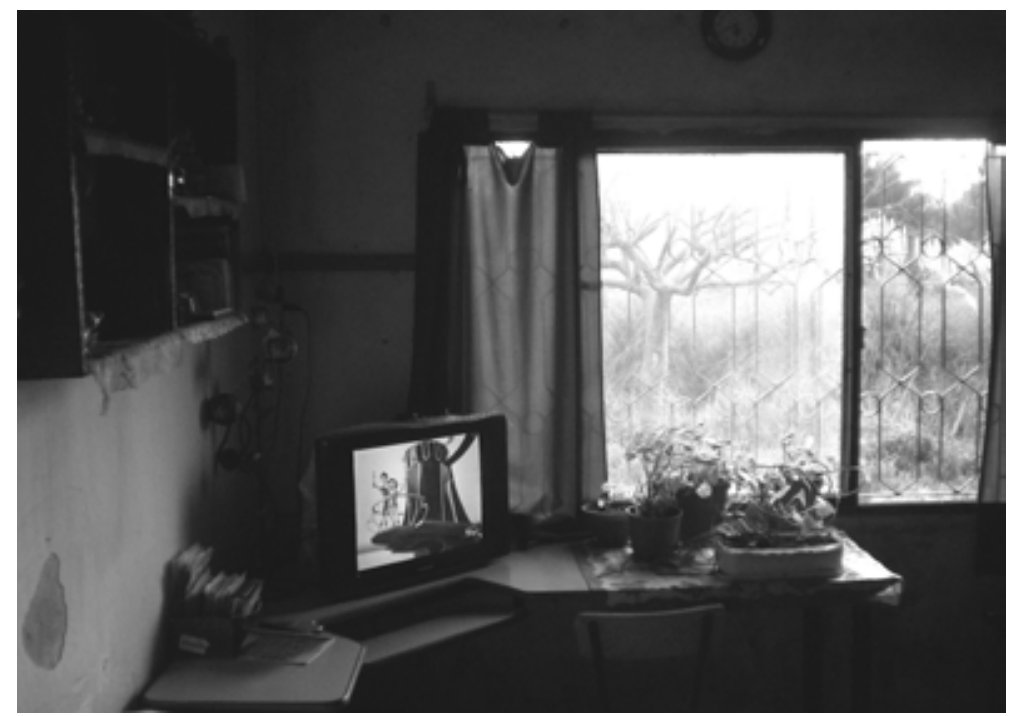

3. Estar de la vivienda: rincón con televisor y ventana exterior.

la nueva vivienda cuente con otras ventajas materiales. Recordemos que las principales inquietudes que tuvieron frente a la inminente mudanza fue el hecho de pasar a tener "vecinos", es decir, a convivir con otros habitantes en viviendas contiguas, ante estos horizontes amplios, cargados de especies vegetales, pájaros y desde hace poco la aparición de nuevos galpones e instalaciones industriales de forma inquietante pero no tanto como para desvalorizar todo lo anterior, por lo menos hasta ese momento.

La pantalla plana del televisor, que captaba la señal digital gracias a la parabólica ubicada en el techo de la vivienda, se combina de forma también por demás significativa con la imagen ofrecida por la ventana, junto al equi- pamiento del mobiliario al estilo de un escritorio para el trabajo con ordenadores, especialmente por la forma de esquinero desplegado en tres partes y la pequeña superficie inferior, característica para el uso de teclados. Las plantas apoyadas sobre este mueble nos dan una señal de las características de su uso, y de la importancia otorgada por los habitantes al componente vegetal de su entorno, el cual es resaltado y se proyecta más intensamente hacia el interior gracias a la combinación de planos generada de esta manera entre un fondo y una figura así definida.

Gracias a ambas superficies imagónicas así dispuestas, se generaba un ambiente distendido, en la combinación del cobijo de un adentro claramente definido y las aperturas a por 
lo menos dos tipos de exterioridades: un afuera contiguo, factible de ser aprehendido corporalmente al salir cada vez que se deseara, con una comunicación sensorial con las especies vivas y los elementos climáticos, incluso sacando un brazo por ejemplo, y otro afuera virtual, desterritorializado por componentes más intensos en su abstracción, conectado a imaginarios con narrativas de diferentes estilos y géneros (Rincón, 2006). Niños y adultos pueden pasar grandes momentos reunidos en un espacio donde proyectar miradas a pequeñas y largas distancias, directas o de reojo, prestando la mayor atención o tan solo contando con el sonido de fondo, cual ritornelo radial con sus velocidades $\mathrm{y}$ ritmos constitutivos de territorialida- des (Deleuze y Guattari, 1997, p. 318), acceder a productos culturales masivos de industrias del entretenimiento como respirar y observar la vegetación circundante, como parte integrante de rituales domésticos. Esto se da en escenarios multimediáticos, para los cuales las nuevas generaciones adoptan agenciamientos ricos en combinaciones simultáneas, en una multiplicidad de pantallas y sus usos (Morduchowicz, 2008, p. 67).

Todo ello quedaba complementado con una suerte de living instalado hacia la otra dirección de la sala, según un juego de tres cuerpos de sillones, dos individuales y uno triple. La estufa terminaba de coronar el espíritu hogareño, aunque no alcanzaba para brindar calor en las noches más duras del frío

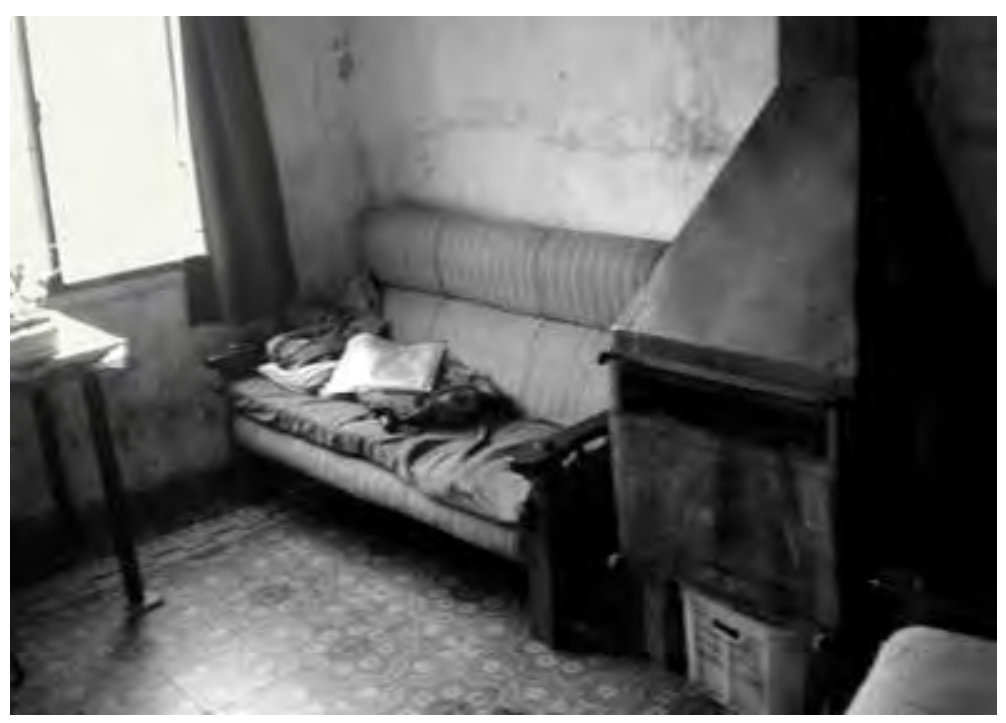

4. Estar de la vivienda: rincón del sofá y chimenea. 
invierno montevideano en esta zona descampada, según nos lo narraron: había que quedarse extremadamente cerca de ella para recibir las bondades de la combustión de la madera en su seno. Así y todo, la espacialidad generada entre ella y la pared de la ventana, donde se disponía el sofá de tres cuerpos, donde el etnógrafo rápidamente se sintió seducido a instalarse una vez que se dispuso el tiempo para el más largo y distendido diálogo posible, era un genuino "rincón". Según Bachelard: "todo rincón de una casa, todo rincón de un cuarto, todo espacio reducido donde nos gusta acurrucarnos, agazaparnos sobre nosotros mismos, es para la imaginación una soledad, es decir, el germen de un cuarto, el germen de una casa" (Bachelard, 2000, p. 126). La poética social en este caso muestra su sofisticación, por otra parte tan recurrente, al disponerlo junto a la luminosidad y el paisaje, la pantalla y el ojo, que constituye la ventana más importante de la vivienda.

El rincón no es sinónimo de oscuridad necesariamente, o por lo menos, cuando se logra una composición con este tipo de diseños se puede habitar más allá de la dialéctica unidimensional del adentro y el afuera, y saborear, sentir con todos los medios posibles, las sutilezas de fronteras, umbrales y barreras que al mismo tiempo nos separan y conectan, como todo medium (Flusser, 1994, p. 185). El rincón aparece como el corazón de toda intimidad, y ciertamente el resguardo y agazape son genuinamente constitutivos de la función del habitar, así como el estar se muestra de la forma más desprendida del transitar, donde los tiempos parecen eternizarse, el movimiento del devenir ralentizado, pero esto no quiere decir que cese, pues también siempre se trata de una temporalidad.

En dirección diagonal a este rincón por excelencia, las dos puertas de las habitaciones guardaban, como decíamos, la máxima discreción, manteniéndose como los últimos espacios vedados a todo visitante. Insistir o no en penetrarlos dependió de las circunstancias del encuentro, los fines de la investigación, la calibración técnica del etnógrafo. En este caso no hubo dudas en dejar las cosas así, máxime con la presencia de alguno de sus moradores detrás de las puertas.

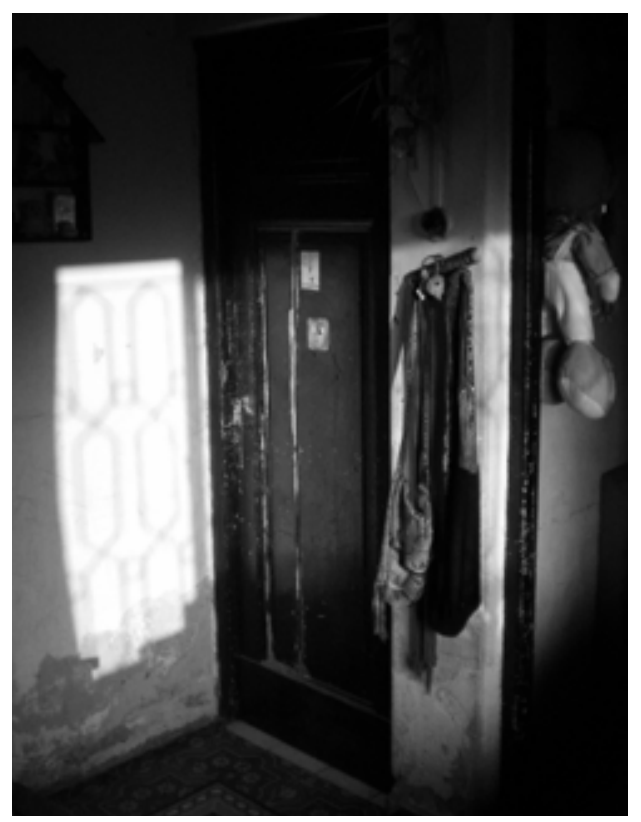

5. Puertas hacia los dormitorios. 
Y en el último de los cuatro triedros, geométricamente expresado, otro rincón, en este caso diseñado como el espacio sagrado del hogar, donde se realiza el culto a los dioses y espíritus. "Mi señora es de religión" me comentaba Pérez, mientras me permitía fotografiar el altar umbandista. Se trata de una religión de origen afro-brasilero, o "culto de posesión" en la terminología de Pi Hugarte, con un grado de institucionalización por demás considerable luego de décadas de paulatina transnacionalización a partir de la segunda mitad del siglo XX en adelante (Oro y Scuro, 2013, p. 24). La integración de lo espiritual en la vida doméstica, sin necesidad de encontrar un ámbito aislado para ello, requiere igualmente de la conformación de un entorno propio, un rincón donde territorializarse. Si bien no se trata de algún genius loci en el sentido etimológico del término, o sea de alguna entidad sobrenatural directamente atribuida al cuidado de la espacialidad en cuestión (NorbergSchulz, 1984, p. 18), no deja de irradiar e incidir en general sobre su sentido. Como veremos más adelante gracias al siguiente caso, la cuestión de la espiritualidad e incluso de religiosidades instituidas en amplios sectores sociales, asoma como una de las más relevantes tras los velos que protegen la intimidad del hogar.

Además del estar, integrado a una cocina contigua, el baño y los dos dormitorios (uno conseguido a partir de la adaptación de lo que fue quizás el antiguo recibidor de la pequeña casa

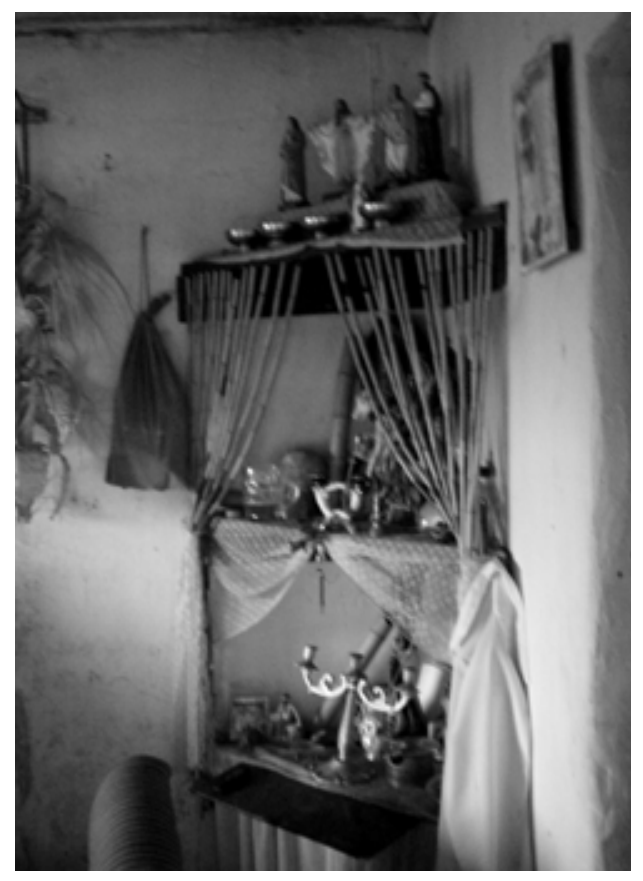

6. Rincón con altar umbandista.

rural), nos encontramos con dos ámbitos espaciales más. Uno de ellos era una habitación a la que parece siempre se accedió desde dentro, pero en la cual era difícil identificar su antigua función. En el momento era utilizada como el espacio de depósito de los objetos y cosas necesarias para el sostén de la vida cotidiana y que no deben estorbar con su presencia. El deterioro de las paredes por la humedad general era de los más notorios de toda la vivienda, a pesar de contar con una pequeña banderola al estilo de las que se ven en los baños (lo que puede darnos algún indicio de su situación pasada).

Sea como fuere, es evidente que este ambiente no podía ser utilizado para prácticas que insumieran mucho 
tiempo, ni en condiciones de máxima relajación e intimidad, como la alcoba o dormitorio. Además de encontrarnos con objetos como una bordeadora - para mantener a raya el pasto que crece por todo el alrededor- $y$ otros similares asociados al cuidado cotidiano y de mayor frecuencia del hogar y su entorno, lo más relevante era la ropa de toda la familia. Para ello utilizaron una estantería liviana como ropero, lo que implicaba que las prendas fueran visibles, y asemejaba la situación a la de un exhibidor de mercadería comercial. Esto, junto a los conceptos e ideas generales que María y Pérez expresaban en el diálogo paso a paso, reafirmaba la idea de la poca o nula presencia de extraños en la casa comúnmente, y con ello la confianza en los vínculos que se iban estableciendo conmigo, el etnógrafo, que así vislumbraba algo más de sus habitares íntimos.

El otro ámbito particularmente sensible a la investigación es el baño. Una de las obras constructivas más importantes realizadas por los habitantes fue justamente cambiar el lugar de la puerta de este. Con anterioridad, como en las tipologías de la gran mayoría de viviendas rurales, se accedía desde fuera, lo que para la cotidianidad según sus estilos y hábitos de vida resultó un grave inconveniente. Pérez, según nos narraba ante el marco de la puerta, se atrevió a "meter mano", como dice, trasladando la hoja de la puerta de un marco a otro, una vez que abriera la pared, y cerrando el otro agujero resultante con ladrillos.
Esto les transformó la vida como pocos de los cambios realizados, así como transformó la misma estructura arquitectónica de la morada en su totalidad. A partir de esta intervención es que también se anima a seguir adelante con otras modificaciones. Imaginemos los efectos de poder contar con el acceso al baño sin tener que salir a cielo abierto, para el aseo, en los momentos más gélidos del invierno, a toda hora, en aquellas circunstancias de mayor intimidad, donde el sujeto se encuentra consigo mismo en soledad con su propio cuerpo, por ejemplo, o el cuidado de aquellos miembros de la familia que más lo necesitan por estar aún ganando autonomía (como los niños pequeños) o perdiéndola (como una anciana).

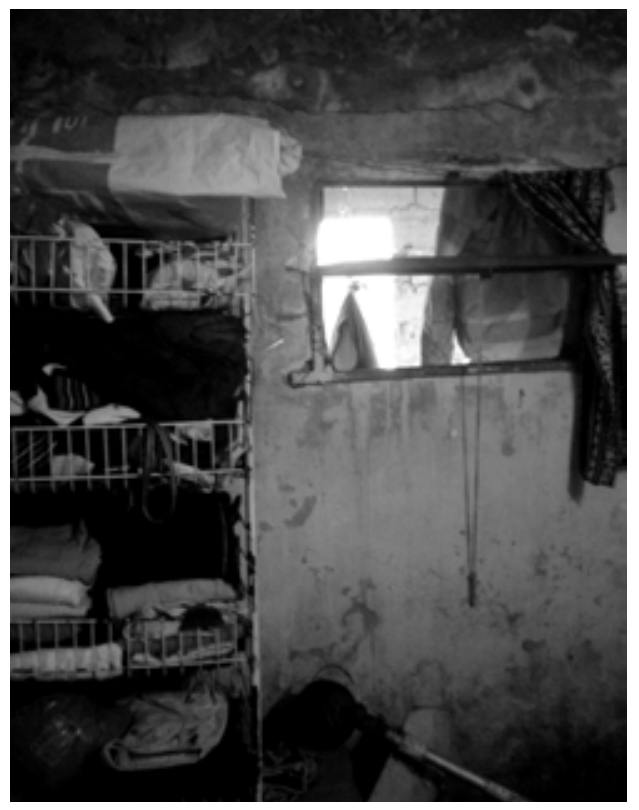

7. Habitación tipo vestidor y depósito. 


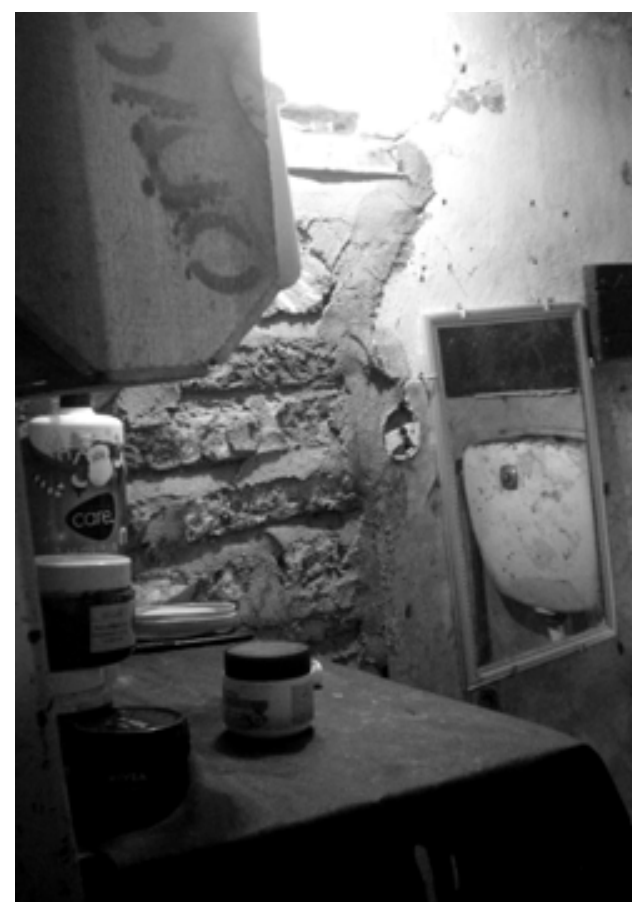

8. Baño.

El recorrido nos llevó, finalmente, hacia la puerta principal de la vivienda, por donde había ingresado unas cuantas horas antes, justo detrás del estar principal. Nuevamente recordaron los duros momentos del último gran temporal sufrido en estas latitudes, en el año 2004, asociándolo al acceso al baño antes descrito. La posibilidad entonces de transitar, de poner en comunicación en tanto entrar-y-salir, de hacer uso de los espacios según las necesidades definidas en el marco de sus formas de habitar, era una de las problemáticas centrales en la reflexión y análisis que íbamos tejiendo entre los tres mientras dialogábamos en marcha. Entre ambos una narración sobre la noche más cruda de este temporal fue esbozándose, acompañada de instantes de reconstrucción actoral a cargo principalmente de Pérez, y contando con la puerta como insumo para ello. Esta, recordaba, se resistía a permanecer cerrada, abriéndose violentamente por efecto de los imponentes vientos que azotaron la región, más en estos parajes semirrurales próximos a la costa rioplatense.

Esta puerta también había sido modificada por ellos. Según narraron, cuando se constituyeron como pareja y pasaron a vivir allí, lo que había en su lugar era una chapa de metal que trancaba con un palo de madera. Esa noche rememorada de temporal, tuvieron que sostenerla cada uno mientras el otro salía fuera para ir al baño, por entonces sin el acceso interno construido. El relato, sus poses siguiendo una suerte de memoria corporal muy potente, mis propios recuerdos de esa noche donde me tocó experimentarla y demás, me hicieron imaginar a un par de astronautas enfrentados a lo que Blaise Pascal sentenció con contundencia como el terror frente al "silencio de los espacios siderales". Ciertamente, el exterior de la pequeña vivienda precaria era entonces un afuera infinito, hostil y aplastante. El medioambiente se convirtió esa noche, como en toda situación de catástrofe, en una entidad terrorífica, una suerte de caos primordial y final, apocalipsis donde todo es engullido. 
Así de fatal se experimenta un ambiente construido cuando las condiciones generales, las materialidades y los procesos subjetivantes asociados en una misma red de prácticas, acciones y cosas (Latour y Yaneva, 2008) no logran sostener la mínima condición para la vida. Esto resultó ser una de las características generales de aquellos participantes del Plan Juntos, orientado a quienes enfrentan este tipo de situaciones críticas, incluso por debajo de muchos otros en condiciones de pobreza y exclusión. Algo de heroico, por supuesto, tiene este relato, junto a lo dramático del contexto, algo de satisfacción por la superación o por haber podido sobrevivir a tales peligros y riesgos. Pero un deseo y una necesidad de superación motivaron a María y Pérez a buscar siempre una solución

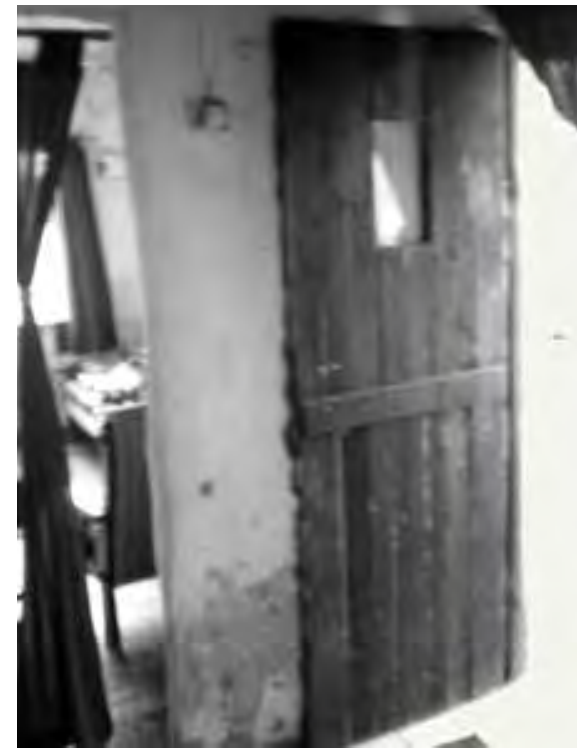

9. Actual puerta principal. habitacional y existencial en general, para sí y sus seres más queridos.

La última estancia visitada fue una habitación que había quedado a medio construir, por efecto de los nuevos proyectos de vida una vez que ingresaran al proceso transformador del Plan. Diseñaron una suerte de gimnasio para el hijo adolescente que adoptaron de hecho juntos, y que se encontraba por entonces jugando al fútbol en las ligas inferiores de un club local cercano, de segunda división profesional, el Huracán del Paso de la Arena. Cabe destacar los objetos allí presentes: la bolsa de arena para el entrenamiento, el banco de madera similar al encontrado en los vestuarios deportivos, la bandera del Club Atlético Peñarol, toda una institución en diversas disciplinas, incluida el boxeo.

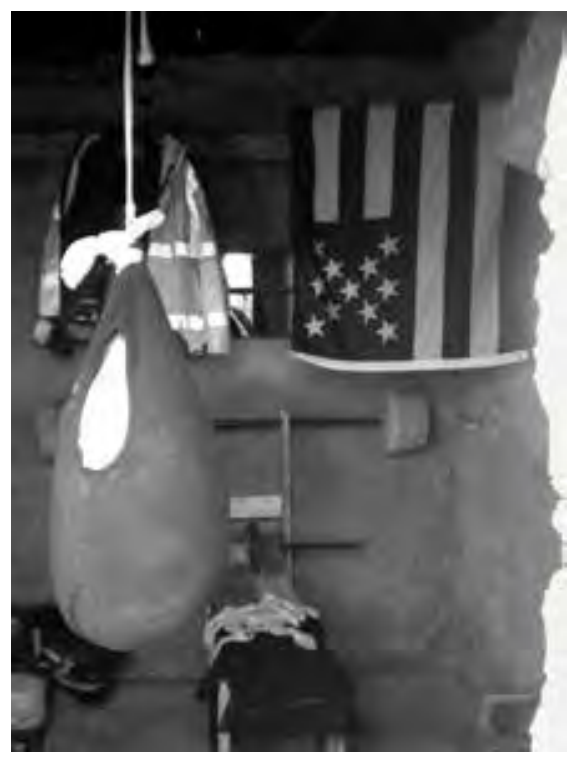

10. Gimnasio. 
Un poco más de medio año después, nos volvimos a encontrar, primero con Pérez y luego a los meses con toda la familia, en la nueva vivienda construida en el marco del Plan Juntos en el llamado "Barrio Amanecer". La antigua casa fue pasada a una amiga de María, para quien a pesar de la condición de precariedad extrema de la construcción le significó una solución habitacional. De esta manera también mantiene un vínculo con aquella vivienda, su intimidad, sus entornos tan queridos, los afectos asociados por tantos años, mientras habitan un nuevo sueño. Al respecto, la tesis de Bachelard (2000) y su peculiar fenomenología, resulta por demás sugestiva: una vivienda es un ámbito de vida que invita a la ensoñación, al soñar despierto, a proyectarse constantemente. Esto tiene que ver con lo que contemporáneamente consideramos como "diseño de ambientes para la vida" (Ingold, 2012), o "existencial" (Álvarez, 2013b), que explicita esta dimensión de composición y concreción de las formas de habitar. "La casa me tiene muy entusiasmada, no puedo parar" me decía María una vez que nos encontramos en una jornada de llamada "obra solidaria", donde ella, con su pareja y otros participantes del Plan, se ponían "manos a la obra" para terminar de construir la vivienda contigua a la de ellos, destinada a una mujer sola, madre de un hijo con un padecimiento crónico, y por tanto exonerados de tener que cumplir con horas de trabajo por tales causas.

La vivienda de la pareja estaba rebosante de vida, la madre ya anciana disfrutaba ordenando meticulosamente los utensilios de cocina y lavando

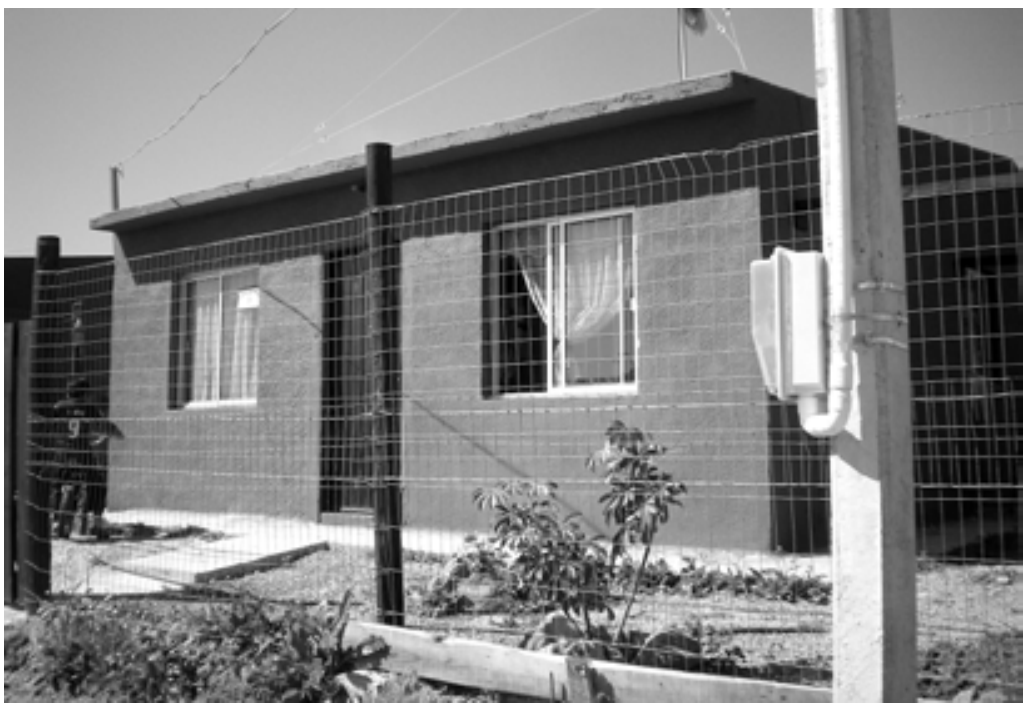

11. Nueva vivienda en el marco del Plan Juntos. 


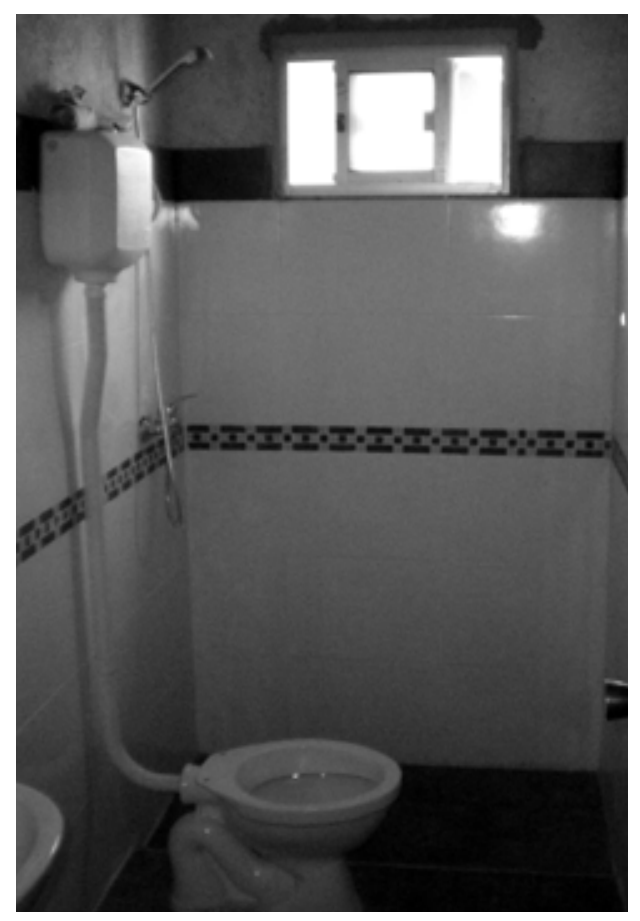

12. Baño por estrenar, en la nueva vivienda.

todos los trastos, el pequeño niño jugaba andando en bicicleta, con un teléfono móvil sin chip, con su ordenador portátil del Plan Ceibal de las escuelas públicas uruguayas, y el joven hijo adolescente anotaba con entusiasmo la dirección de mi blog para acceder a los textos que ya había generado en función del trabajo de campo de esta investigación. Por supuesto que no existen finales felices en la realidad, pero tampoco podemos dejar de aprehender y comprender las dinámicas del deseo, el goce y, como decíamos, la ensoñación que tan oportunamente identificó Bachelard (2000) para los fe- nómenos aquí planteados. Problemas y dificultades con la nueva vivienda, tanto hacia el interior como hacia el exterior, son parte de una realidad siempre compleja, ambigua y ambivalente. Pero el salto cualitativo para hacer de esa construcción un nuevo hogar, lleno de amor y poesía, es tan real como todo lo demás.

\section{El fuego interior y el taller de oportunidades}

El segundo caso que pondremos a consideración de esta etnografía es el relativo a otra pareja que también reside actualmente en una de las viviendas construidas en el marco de las obras del Plan Juntos, a un par de calles de distancia de la de María y Pérez. Se trata de Juana y José, cercanos ambos a los treinta años de edad, quienes junto a sus tres hijos se encontraban anteriormente en lo que se denomina "situación de calle", es decir, sin un espacio de cobijo mínimamente seguro y permanente. Según lo narraron, en los últimos tiempos habían estado durmiendo en uno de los baños públicos ubicados en la playa del Cerro, la más cercana y emblemática de la zona. Su caso es uno de los representativos de los considerados como críticos desde el punto de vista de la organización del Plan. Efectivamente, como ellos también lo evaluaron, no fue fácil la inserción en la dinámica colectiva que se les planteó. Ambos son oriundos de la zona oeste del de- 
partamento capitalino, han vivido en diferentes territorios que la componen (incluido en el que se encuentran ahora), siguen teniendo familiares cercanos por allí, pero esto no les aseguró un arraigo capaz de solventar soluciones habitacionales más o menos estables. Nómades en su propio espacio de nacimiento, no sin idas y venidas por fuera de este, quedaron en una situación extremadamente precaria, especialmente para sus niños.

Estuvieron a punto de quedar fuera del Plan Juntos incluso, fuera por tanto de la última de las posibilidades, ya que no existe otra política habitacional que intente llegar a lo más hondo de la pobreza estructural y la indigencia. Discusiones con capataces de obra, algunos de los cuales a su vez se inmiscuyeron en la relación de pareja debido a un supuesto abuso por parte de él hacia ella, incumplimientos con los horarios y tareas constructivas en colectivo, todo lo cual llevó a una movilización importante por parte de trabajadoras y educadores sociales, e incluso abogados del Plan para encontrar una solución. Evidentemente, cada una de las partes posee una versión con sus propias explicaciones de los acontecimientos involucrados en estos conflictos. Lo interesante de todo ello es que finalmente se mantuvieron dentro del Plan, alcanzando a hacer realidad el sueño de la casa propia, para felicidad de todos.

Ya había entrado en contacto con Juana en una de las jornadas del trabajo de campo en "Barrio Amanecer", y en el diálogo informal generado con ella había salido la cuestión de que estaban construyendo la vivienda adjudicada para ella y su familia nuclear a pocos metros de allí, saliendo del entorno principal en lo que vendría a ser una de sus espaldas, en el extremo de una hilera de poco menos de una decena de viviendas contiguas. Algunas vecinas de este entorno principal de la intervención en la microzona, habían bromeado conmigo sobre lo especial que resultaba, por su carácter $\mathrm{y}$ actitudes, por ejemplo apareciendo en las noches de los fines de semana gritando festivamente con el afán de arengar al vecindario. En esta oportunidad, mientras estaba participando de una jornada de trabajo colectivo en una de las viviendas, junto a varios de los vecinos ya instalados allí, se hizo presente junto a su hija más pequeña, con muy buen humor y demostrando ganas de participar y generar lazos.

Es así que volvimos a entrar en diálogo, y luego de que las tareas principales del grupo de obra acabaran, le consulté si era posible ir a conocer su hogar, entrevistándola a ella y a su compañero en su propio ámbito doméstico. La idea le resultó fantástica, y hacia allí nos dirigimos. Una vez que llegamos nos encontramos con su pareja, José, tomando mate dulce en un vaso de vidrio, compartiendo lo que restaba de la mañana y el comienzo del mediodía junto a sus otros hijos de mayor edad, en la letanía del sábado de descanso general. La bienvenida 


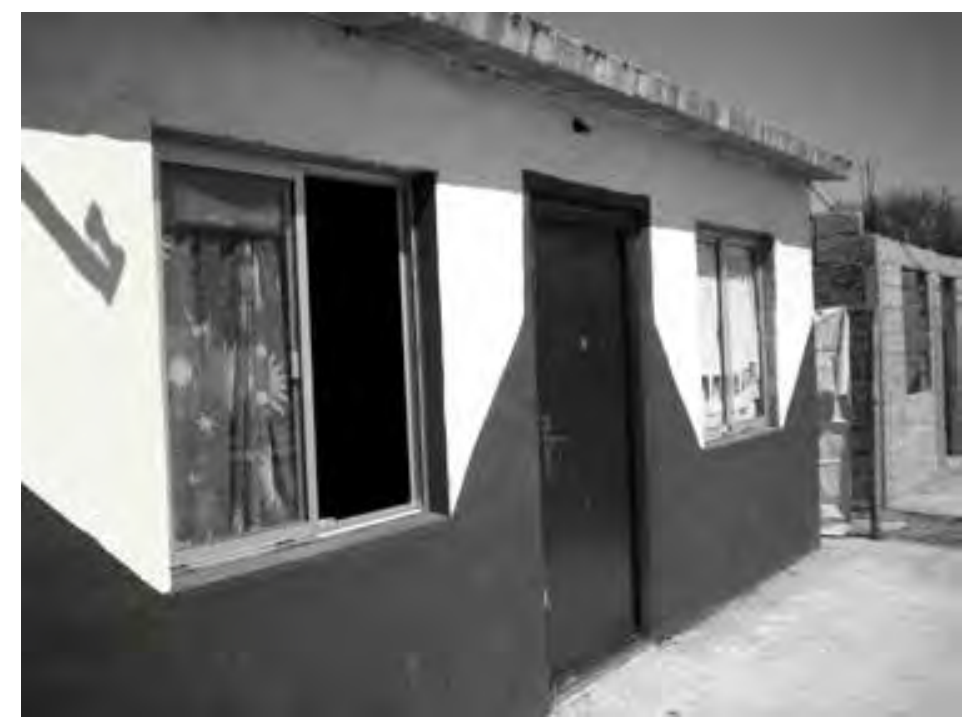

13. Fachada de la nueva vivienda de Juana y José, en el marco del Plan Juntos.

fue igual de grata, y mientras las criaturas pequeñas siguieron con sus actividades lúdicas, los adultos nos encomendamos en una larga entrevista en profundidad con momentos de mayor estancia, nuevamente en lo que sería el espacio del estar de la nueva vivienda, y otros más de desplazamiento por sus otros espacios, en una nueva entrevista recorrida o recorrida entrevistada.

Desde la llegada al lugar me llamaron poderosamente la atención dos cuestiones: en primer término, que esta fuera la única vivienda concluida y habitada plenamente de la hilera, frente a las demás en franca distancia en los respectivos procesos constructivos; en segundo lugar, la forma en que sus habitantes habían pintado la fachada, con los colores blanco y celeste fuerte, según segmentos diagonales a los lados de las ventanas.

Sobre el primer aspecto, José fue muy elocuente acerca de la elección del "mejor" predio para la vivienda particular dentro de las posibilidades. Según él, una serie de factores incidieron en ello. La ubicación en el contexto urbano, el estar lo más cerca posible a la avenida-que es más una ruta secundaria- la cual conecta a su vez con la avenida principal de toda la zona cerrense y de allí a toda la ciudad, fue planteado como fundamental. Después, la calidad de la sedimentación, pues según él observó cómo rellenaban correctamente ese sector en su momento los camiones con material al servicio del Plan, y 
cómo no lo hacían de buena forma en los demás terrenos contiguos.

Recordemos que a pocos metros hay una pequeña cañada regularizada que es el eje central del "Barrio Amanecer", y un brazo de esta se abre hacia esta dirección, en lo que antiguamente era un típico ambiente de humedal (Álvarez, 2014b). Este era uno de los cuestionamientos a los procedimientos del Plan. José indicaba señalando los diferentes materiales utilizados en su vivienda y en la más cercana que se podía ver tras la puerta secundaria de la cocina, la cual se encontraba abierta, para afirmar cómo tuvo que trabajar según él en solitario pero con grandes resultados, al lograr una obra de mayor calidad en materiales y terminaciones, tanto en la estructura de muros como en el mencionado suelo y en el techo sobre nuestras cabezas.

En relación a la estética de la fachada, volvería a encontrarme con las diagonales y esos colores dentro, con lo que constituye el corazón espiritual de la casa, el hogar propiamente dicho (Segalen, 1996), aunque no se cocine allí con mayor frecuencia. Esta es, hasta el momento, la gran obra de autoconstrucción en el interior de la vivienda, la que más la singulariza al distinguirla de las otras y dotarla de un carácter particular, conforman-

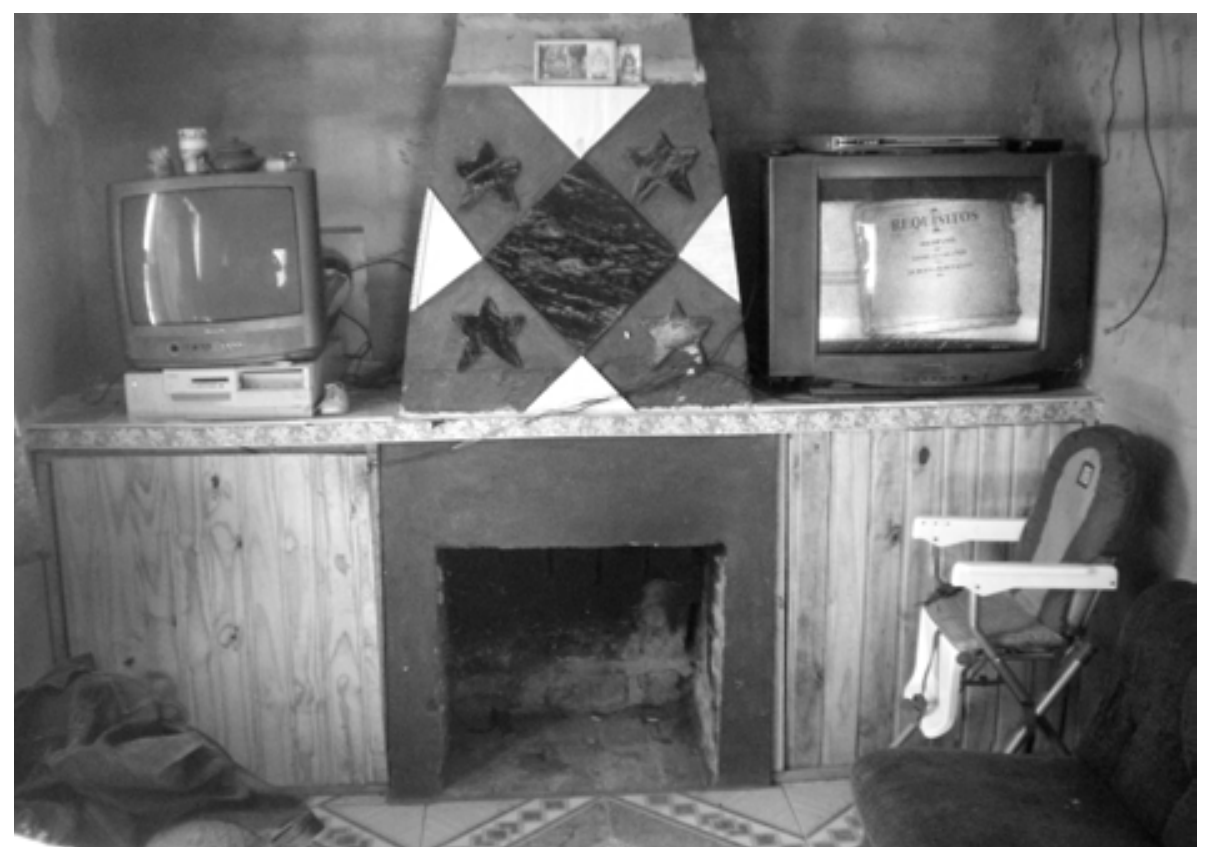

14. La estufa y su entorno. 
do así una espacialidad irrepetible. Orgullo de la casa, la estufa ha sido decorada en su chimenea también con diagonales y pintada con el blanco y el celeste fuerte de la fachada, a lo que se suman estrellas negras. La parte inferior ha sido revestida con tablillas de madera cual lambriz, de uso masivo en la decoración de interiores en estas regiones del continente, por lo menos hace varias décadas. El revestimiento cerámico del suelo también fue obra de él y objeto de admiración por todos los adultos presentes en el momento. Pero volviendo al diseño decorativo de la chimenea, no pude dejar de tener reminiscencias de formas y colores que me hacían traer a la memoria afectos claramente asociados a rasgos estéticos propios de ciertas manifestaciones culturales.

Luego, con el paso del tiempo y analizando el material de campo, me percaté de que se trataba, en principio, de la cultura afro-uruguaya, asociada directamente al candombe $\mathrm{y}$ a todo su universo de sentidos y valores, sin dejar de lado las posibles mezclas de otras vertientes procedentes del Brasil ya más ligadas a la amplia y permeable religiosidad popular. La presencia de la tradición afro-rioplatense es obviamente más directa, se puede encontrar en el diseño de la indumentaria con la que desfilan los tocadores de tambor llevándolos colgados, y por supuesto el motivo de las estrellas, que como se ha señalado, es un elemento de probable procedencia islámica junto a la media luna (Olivera, 2005). Estos elementos pertenecen a imaginarios amplios $\mathrm{y}$ extendidos que pueblan de íconos y otras entidades imagónicas, un universo figurativo al que se apela cuando las condiciones lo permiten. Y este parece haber sido el caso, junto, por supuesto, a otros factores desconocidos por nosotros, como el acceso a ciertas pinturas y no a otras, o la destreza ante el pincel o la brocha para delinear tal o cual forma. De cualquier manera, estamos apelando a la existencia de un pragmatismo existencial, ubicado en un campo de inmanencia de puras prácticas, dentro de las cuales todos estos elementos actúan y generan sus propios agenciamientos (Deleuze y Guattari, 1997), haciendo uso de objetos y formas en una suerte de arte espontáneo o artesanía vernácula.

Que esto ocurra en la decoración del objeto en el cual se crea el fuego puede dar para muchas especulaciones. De todas formas, José enfatizaba lo bien que lo pasan todos allí, disfrutando de esa espacialidad como en el momento en que nos encontrábamos: "el sol entra por la ventana, ¿y sabés cómo pega, con un vinito", a lo que su compañera lo interrumpió con un poco de pudor por mi presencia y dijo: "Ah... cállate, ¿qué va a pensar?". Yo me sonreí y asentí con la cabeza. No podía más que asociar lo que me estaba queriendo transmitir José con las posibilidades de un habitar según una espacio-temporalidad que así lo permitía, al distenderse en una intimidad donde sentirse dueño de su propio cuerpo y espíritu, ese tipo de exce- 
sos cotidianos propios de "aventuras a salvo" en el "confinamiento de los sentidos" (King, 2008, p. 75). Para entonces no pude aceptar un mate dulce más de los que veníamos ingiriendo sostenidamente, y mientras Juana se disponía a tomar un baño, preparándose para salir junto al grupo de vecinos del Plan Juntos, que tenían una actividad de socialización en uno de los principales parques de la ciudad, nosotros nos levantamos y comenzamos a recorrer todo el predio, dentro y fuera de la vivienda.

La nueva cocina, como en todos los casos que conocimos en las variaciones tipológicas habitacionales del Plan, se encontraba abierta hacia el espacio más amplio de la vivienda, el que por lo general funciona como estar. Sin dudas es una buena estrategia para la optimización de la superficie y la cualificación de virtuales espacialidades domésticas, donde las actividades de variadas funciones cotidianas puedan combinarse. Si bien ya se observa a ambos lados de la preciada estufa dos televisores y otros aparatos electrónicos, junto a una computadora con su monitor, la cocina concentra la mayor presencia tecnológica. José fue describiéndome cada uno de los electrodomésticos allí presentes, desde la heladera al microondas, haciendo énfasis en la procedencia de cada uno de los objetos y la forma en que él los había reciclado o recuperado, lo que le permitía tener un stock de "comida para los chiquilines".
Gracias a su ingenio, y a sus vínculos con los nuevos vecinos para los cuales ha ido desarrollando diferentes trabajos puntuales de albañilería, instalaciones de este tipo y hasta de sanitaria, siente que ha logrado proveer a su familia de un nivel de confort al que jamás había llegado ni soñado alcanzar. Había pasado de vivir en las calles, a poder contar con un congelador donde me mostró había carne picada y algunos otros alimentos listos para ser utilizados; de percibir y pensarse como incapaz de proyectar una cotidianidad mínimamente previsible para el sustento de sus niños, a esta nueva situación fruto de la vivienda construida en torno al Plan Juntos y su propio ingenio y astucia de restaurador.

Él y su compañera no se presentaron como hurgadores de residuos, pero estas pautas tienen mucho de ello, y es algo que va más allá de la actividad específica en tanto caracteriza procesos de subjetivación muy presentes en estos territorios de la periferia urbana. Lo mismo el trabajo con las manos, que va de la clásica carpintería a la electricidad, y en algunos casos incluso al software y el hardware (Álvarez, 2013a, pp. 179-184). De todas formas, según la narración de ambos mientras recorríamos el sitio, se habían dado una serie de accidentes importantes: la heladera no funcionó correctamente desde el principio, y tuvieron que tirar comida echada a perder por falta de frío, así como alguno que otro cortocircuito generó fuego puntualmente, y quemó algunos electrodomés- 
ticos en la marcha. Algunos de estos vecinos a los que hacía referencia como los antiguos propietarios de esos bienes, ya los conocía en el transcurso del trabajo de campo de esta investigación, y fue muy interesante identificar los vínculos transversales que se tejieron en estos nuevos territorios de convivencia. Una suerte de fijación con estos objetos electrodomésticos, que si bien puede entenderse en relación al consumo en los estándares de clase media a los que parecen asomarse, no deja de estar impregnado de esa satisfacción por recuperar y poner en funcionamiento lo que parece estar destinado a perderse. $Y$ es que ambas cuestiones van juntas, dentro de un nuevo sentido de confort que se viene ajustando cada día (Miller, 2008), y necesariamente de forma incompleta (Pezeu-Massabuau, 2012).

Junto a estas cosas tan significativas, cargadas de relaciones, prácticas, actantes y todo lo relativo a las redes humanas y no-humanas de contextura de lo real rizomático (Deleuze y Guattari, 1997; Latour y Yaneva, 2008), me encontré como en el caso anterior con una fuerte presencia de imaginería religiosa. Esta, junto a los diseños de la fachada y la chimenea, dotaban de cuerpo a la estética global del lugar, poniendo nuevamente en consideración el papel de lo religioso en el diseño de los universos de existencia más íntimos, evidenciando cómo "La religiosidad compone tradicionalmente el sistema de sentidos que configura la casa, en una poderosa y englobante

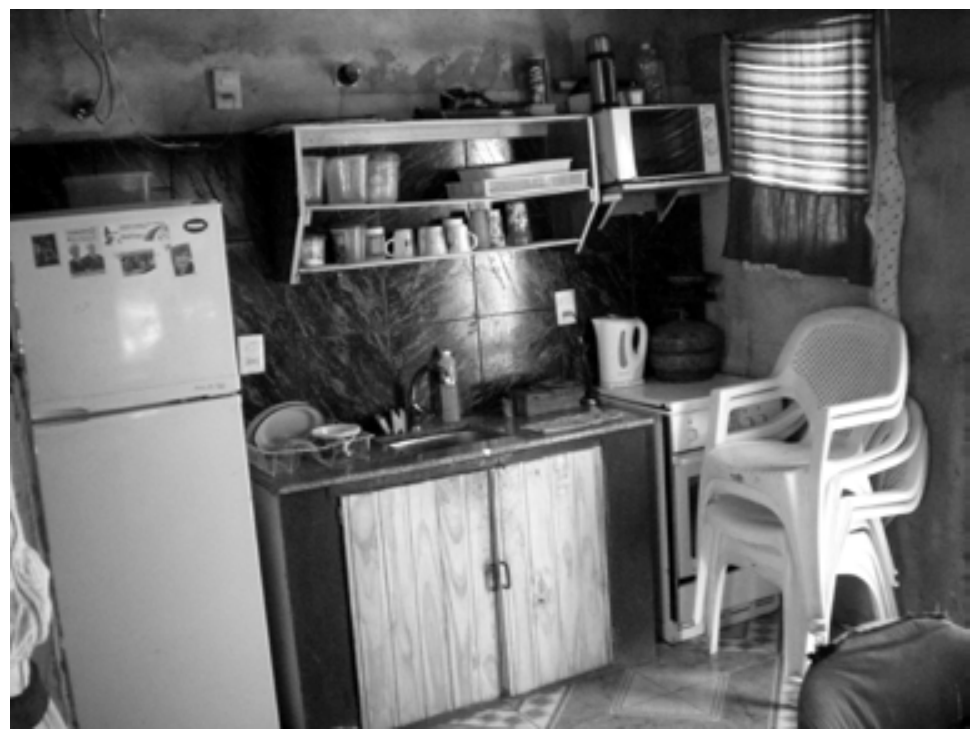

15. Cocina. 


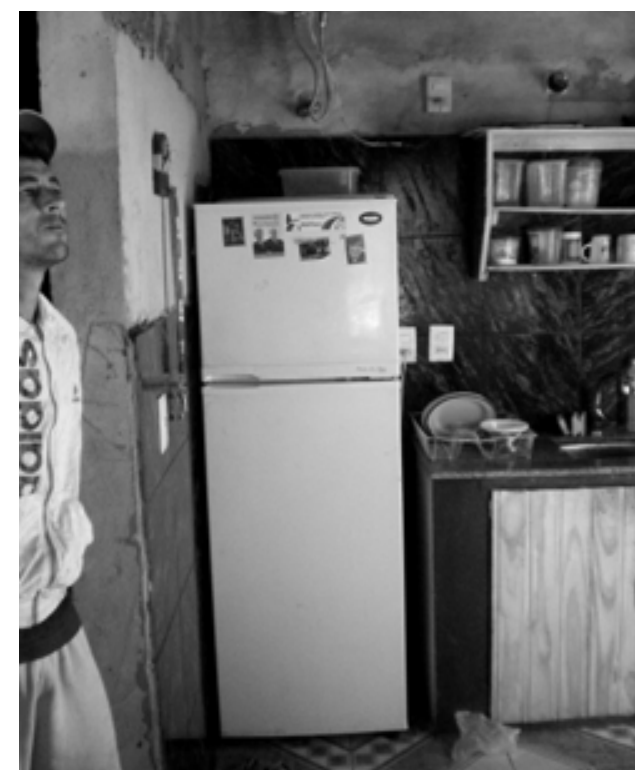

16. Cocina en dirección al estar.

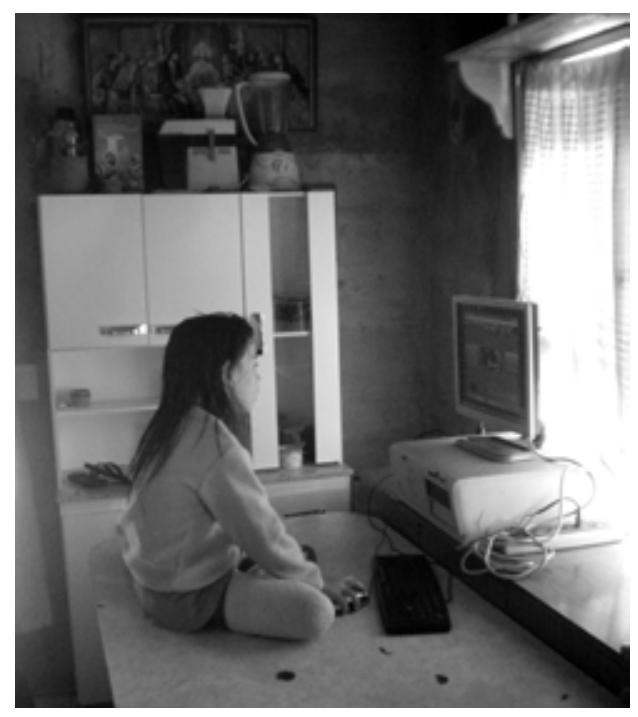

17. Jugando en el ordenador. dimensión moral" (Duarte y Gomes, 2008 , p. 180) ${ }^{3}$. De una gran carga afectiva, los símbolos comunican en primera medida a los propios habitantes con las entidades correspondientes, con posibles comunidades de fieles, así como a potenciales rivales que intenten alguna conversión en estos territorios "populares" donde conviven catolicismo, umbanda y pentecostalismo en más o menos pluralismo (Duarte y Gomes, 2008, pp. 181-186).

Frente a mi pregunta al respecto, de por qué tenía tales y cuales imágenes de santos y vírgenes, cruces y demás íconos cristianos por toda la casa, José me relató su historia con el consumo problemático de pasta básica de cocaína, y cómo se había "rescatado" gracias a la fe. Había emprendido un viaje peregrino solo, hacia la ciudad de Rivera, fronteriza con Brasil, donde tenía algunos parientes, con el afán de escapar de situaciones y relaciones nocivas al respecto en estos ambientes capitalinos. Parece que allí operó alguna conversión, cierta revelación o proceso iniciático que le permitió centrar sus energías y focalizarlas en construir a la postre un hogar.

Después José me invitó a visitar los propios dormitorios, lo que constituyó para mí otro pasaje a un nuevo umbral de intimidad. Como planteamos en el caso anterior, estos resultan ser los ambientes últimos de resguardo y cobijo

3 Traducción del autor. 


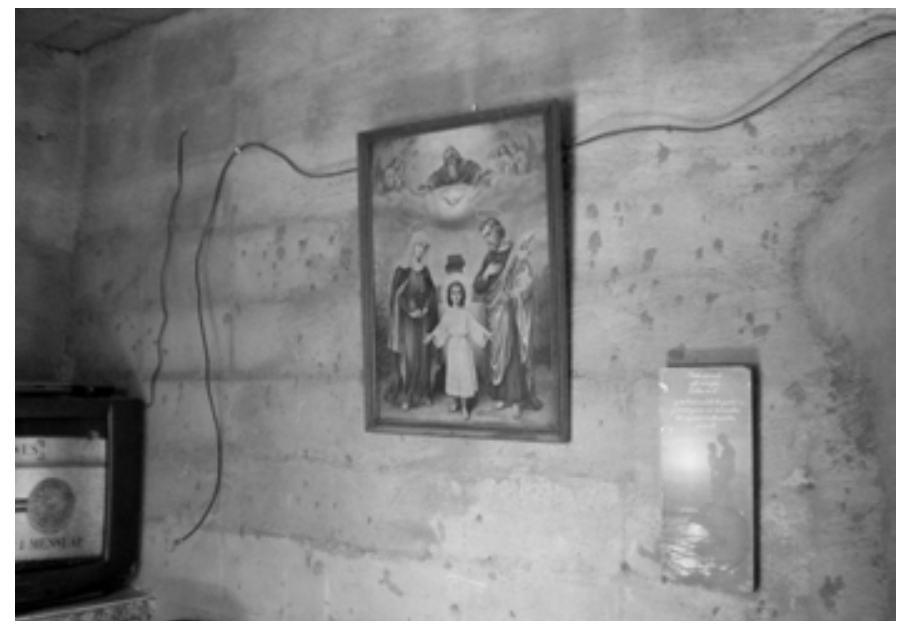

18. Pared del estar.

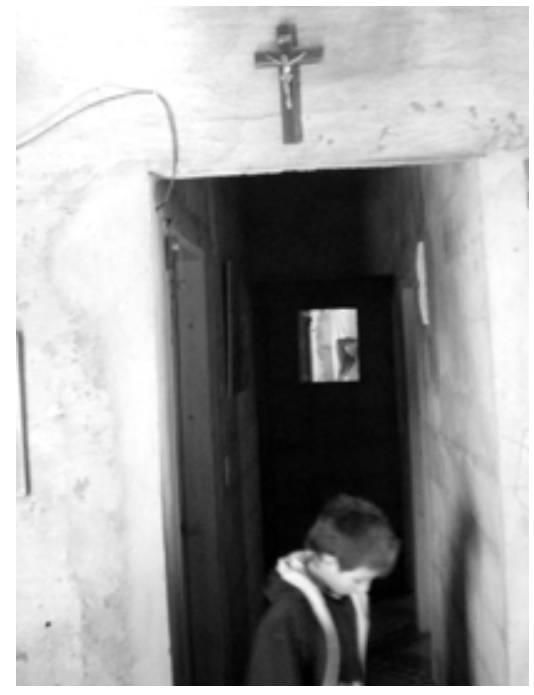

19. Pasillo de distribución, entre el estar y la cocina, con baño al fondo.

del habitar, y mi intención epistémica y ética siempre fue la de sostener dicha realidad. De todas formas, me negué a mí mismo a realizar fotografías en estas situaciones, para no abusar de su gran amabilidad y compromiso con la propia investigación, con "el libro" que estaba escribiendo. Sí me quedó la misma sensación de alegría que sentía por el hecho de poder ofrecer a sus pequeños unos entornos espaciales propios, nuevamente almacenar sus bienes más íntimos, en especial la ropa, así como brindarles más tecnología doméstica: televisores reciclados. A mí me parecieron cuartos extremadamente pequeños, pero comprendí el salto cualitativo que significa para él y su compañera el poder contar con tres dormitorios bien definidos y todo lo relativo al resguardo y el cobijo que da la paz del habitar en tales condiciones, tal como lo expresa uno de los sentidos del término (Heidegger, 1994). A la alcoba principal no me llevó: seguía existiendo algo vedado para el visitante extraño, a pesar de todo.

Salimos finalmente hacia el patio trasero de la vivienda, común a toda 


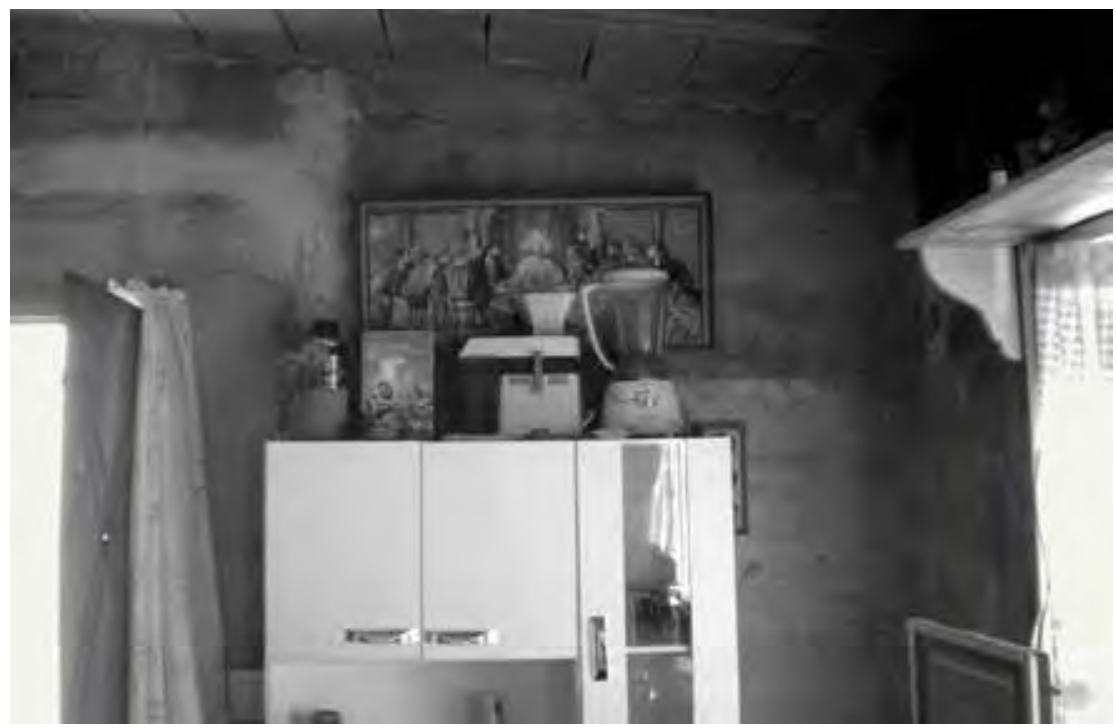

20. Detalle del sector de la cocina, junto a la puerta secundaria.

la tira en construcción de esa calle, así como en muchas de las otras ubicadas en la centralidad lineal del "Barrio Amanecer". En este caso, estábamos de espaldas a algunas de las viviendas construidas en la intervención estatal que tuvo lugar anteriormente allí, la que dio génesis al territorio en cuanto tal (Álvarez, 2014b). Un alto muro permitía contar con una barrera absoluta hacia esa dirección, algo por demás valorado por José y su compañera, la cual a esas alturas ya había terminado de tomarse su baño y volvía con nosotros. Este "fondo" ("quintal" en los términos urbanos tradicionales brasileños), estaba sensiblemente valorado para la práctica de varias funciones, las cuales también desde una perspectiva diferente de cómo habitar, pueden considerarse contradictorias, hasta opuestas. Nos referimos a lo que implica un lugar para el ocio y el juego de los niños, para el disfrute de lo que se considere como naturaleza por parte de todos los miembros de la familia, el tendedero de ropa para su secado, y lo que es algo así como un depósito-taller, donde José acopia los objetos que considera interesantes a lo largo del tiempo y se propone restaurar, junto a los clásicos insumos para la construcción que había utilizado recientemente en la confección de un muro lateral. Los objetos de la cocina ya habrían pasado por aquí, seguramente, por el taller de posibilidades, donde se saca y se pone, se abre e investiga, corriendo el peligro también de ir acumulándose no sabemos hasta qué cota o nivel que se considere insostenible. 


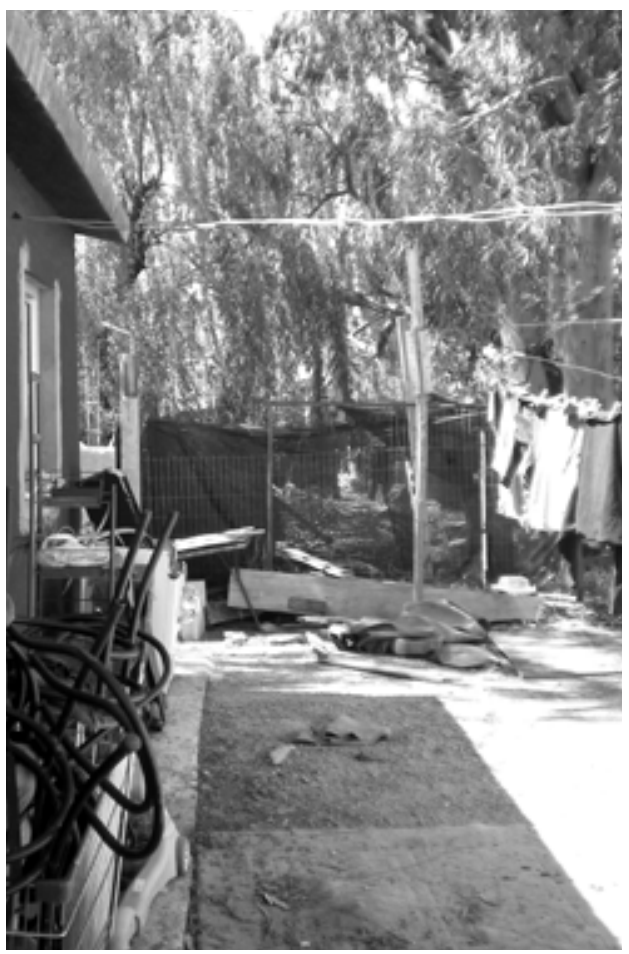

21. Patio trasero.

Por el momento solo se encuentra un juego de comedor para restaurar, dentro de un carro de supermercado, y elementos que son parte del trabajo de autoconstrucción, y una gran manta manchada y rota en varias secciones oficia de alfombra, e intenta disimular, con no mucho éxito, las puntas de los cantos rodados con los que se rellenó el suelo. Pensar que los pequeños niños juegan allí y ver a la más pequeña de todas hacerlo me dio un poco de temor. De todas formas, para sus padres este es el espacio en obra por excelencia, donde proyectan y sueñan despiertos en construir el tan valorado parrillero para asar carnes, como todo montevideano y uruguayo desde las últimas décadas del siglo pasado (Barceló, 1997, p. 249); espacio abierto e íntimo al que se lo ha intentado delimitar desde el principio, lo mismo que encontramos en el caso anterior. "No sabemos quién puede venir a vivir al lado" comentó José, refiriéndose a la vivienda contigua del Plan, a la vez que hacia el otro lado, el del terreno de un vecino que lo ha contratado para trabajos del área sanitaria y con el que dice tener una excelente relación, ya alzó un muro construido con sus propias manos, que dio para dialogar más en profundidad sobre algunos aspectos fundamentales que aquí no podemos desarrollar en detalle.

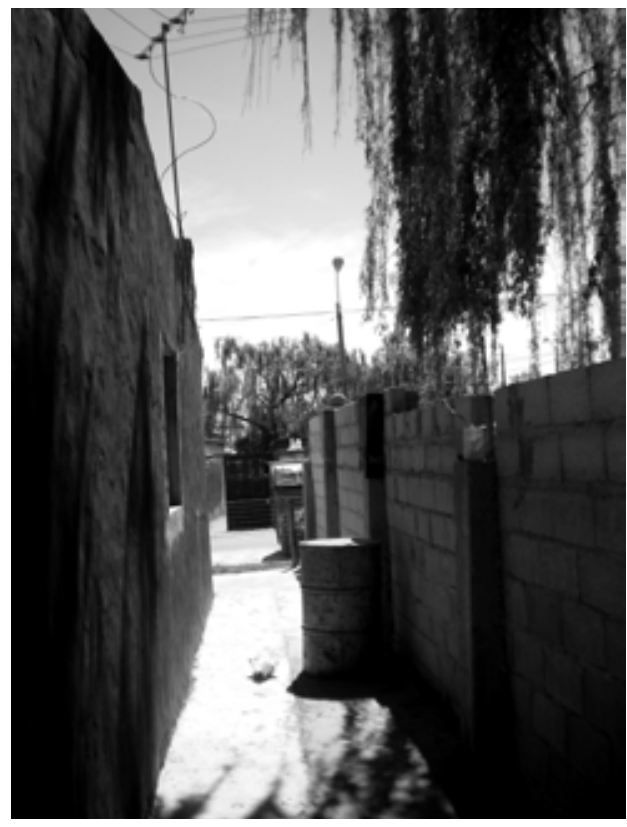

22. Corredor lateral con muro en medianera. 


\section{Conclusiones}

José debe de ser uno de los contados casos de adultos jóvenes del departamento capitalino montevideano que es analfabeto. Me lo narraba en el momento en que expresaba su orgullo y alegría por haber alcanzado a "tener la casa propia". Esto nos sirve para dimensionar el perfil de la población a la que llegó el plan sociohabitacional Juntos, promovido directamente por el presidente José "Pepe" Mujica y financiado con la mayoría de su salario. “¿Y de dónde viene este saber que te ha permitido autoconstruir casi solo tu vivienda?", le pregunté a José, considerando sus propias palabras relativas a ello. "De mi padre" me contestó. Y esto fue relevante en ambas dimensiones: en lo concerniente al universo de la intimidad aquí abordado, como a la construcción de los vínculos intersubjetivos y sus espacialidades "públicas", tanto por lo que comunica hacia fuera su vivienda como por las prácticas de vecinazgo y laborales que informalmente desarrolla en el lugar desde que se instaló.

"Construir ya es habitar" nos plantea Heidegger (1994), y sus implicancias para el conocimiento de los procesos de subjetivación, para las prácticas de composición de nuestros universos existenciales, siempre heterogéneos, es más que considerable: nos obliga a pensar las materialidades en devenir (Latour y Yaneva, 2008), la vida como una obra inconclusa en perpetuo rediseño (Ingold, 2012). Como hemos intentado poner de manifiesto en este trabajo, las "maneras de hacer" en y lo cotidiano (De Certeau, Giard y Mayol, 1999), como conjunto de "tecnologías del sí-mismo" (Foucault, 1995), encuentran en la intimidad un universo privilegiado de exploración de todo ello, siendo también el de más difícil acceso y aprehensión. Estos universos vedados a los "otros", en sus diferentes grados y estados, son el entorno donde se despliega toda la "poética" de la vida social (Herzfeld, 2004) en su máxima potencia, donde todas las formas de mediación posibles se convierten en materia de expresión para comunicarnos a nosotros mismos quiénes somos y quiénes queremos ser, en la ensoñación de ir plasmando una nueva realidad a nuestro alrededor.

El aura de alegría y plenitud cargada de esperanzas y deseos fue una constante en el trabajo de campo más amplio, donde se inscriben estos casos analizados aquí. Se trata de un habitar en movimiento, una intervención habitacional que llegó para sacudir los rincones más olvidados de los excluidos en la sociedad uruguaya, con todo lo conflictivo y complejo que esto conlleva, sin lugar a dudas. Lo cierto es que en las intimidades de sus habitantes podemos encontrar esta activación de la subjetividad, este ponerse en marcha y proyectarse, en contrapuntos diversos con los territorios de lo público, también en construcción y en alcances de mayor abstracción. El tan mentado "empoderamiento" de estas poblaciones encuentra en su dimensión más subjetivante, la de los afectos 
y la sensibilidad, en la intimidad, su muestra más elocuente.

\section{Referencias}

Álvarez Pedrosian, E. (2008). Teoría y producción de subjetividad: ¿qué es una caja de herramientas? En J. Rasner (comp.), Ciencia, conocimiento y subjetividad. Montevideo: CSICUdelar.

Álvarez Pedrosian, E. (2011a). El afuera en el adentro. Estética, nomadismo y multiplicidades. Montevideo: LiccomUdelar.

Álvarez Pedrosian, E. (2011b). Espacialidades: antropología, arquitectura y comunicación. Actas electrónicas de la IX RAM. Recuperado de http:// www.starlinetecnologia.com.br/ram/ arquivos/ram_GT47_E_Alvarez_ Pedrosian.pdf

Álvarez Pedrosian, E. (2011c). Etnografías de la subjetividad. Herramientas para la investigación. Montevideo: Liccom-Udelar.

Álvarez Pedrosian, E. (2013a). Casavalle bajo el sol. Investigación etnográfica sobre territorialidad, identidad y memoria en la periferia urbana de principios de milenio. Montevideo: CSIC-Udelar.

Álvarez Pedrosian, E. (2013b). El ser habitado: diseño existencial y procesos de subjetivación. Anales del III Congreso Iberoamericano de Teoría del Habitar: Entre prácticas, materialidades y significaciones. Montevideo: Alteha/Farq-Udelar.
Álvarez Pedrosian, E. (2014a). Espacialidades emergentes en un territorio disgregado. Lecciones montevideanas sobre habitares, territorialidades y diseño existencial. Anuario de Antropología Social y Cultural del Uruguay, 12, 77-92.

Álvarez Pedrosian, E. (2014b). La gestación de un territorio o de cómo se teje la convivencia. Actas electrónicas del XII Congreso de la ALAIC. Recuperado de http:// congreso.pucp.edu.pe/alaic2014/wp -content/uploads/2013/09/Ponencia\%C3\%81lvarez-Pedrosian-XIIALAIC-Lima-2014.pdf

Álvarez Pedrosian, E., Del Castillo, A., Lamoglie, G. (2014). Laboratorio observatorio del hábitat urbano. Abordaje crítico -desde el proyecto de arquitectura- de la noción de hábitat en la producción de ciudad contemporánea. Actas electrónicas del Seminario Desafíos territoriales contemporáneos. Montevideo: Instituto de Teoría y Urbanismo, Farq-Udelar.

Bachelard, G. (2000) [1957]. La poética del espacio. Buenos Aires: Fondo de Cultura Económica.

Barceló, J. (1997). El hábitat y los estilos de vida. En Araújo, A. M. (coord.), Montevideanos: distancias visibles e invisibles. Habitus psico-socio-culturales de la sociedad montevideana. Montevideo: Roca Viva.

Baudrillard, J. (1993) [1978]. La precesión de los simulacros. En J. Baudrillard. Cultura y simulacro (7-80). Barcelona: Kairós. 
Bestard, J. (2006). Parentesco y nación en la cultura catalana. En X. Roigé Ventura. (Coord.), Familias de ayer, familias de hoy. Continuidades y cambios en Cataluña. Barcelona: Icaria.

Castoriadis, C. (1997) [1996]. El avance de la insignificancia. Encrucijadas del laberinto IV. Barcelona: Pre-Textos.

Chaves Martín, M. Á. (2013). Estudios culturales urbanos. Una aproximación interdisciplinaria. Arte y Ciudad. Revista de Investigación, 3(1), extraordinario, 215-224.

De Certeau, M., Giard, L., y Mayol, P. (1999) [1994]. La invención de lo cotidiano. 2. Habitar, cocinar. México: Universidad Iberoamericana.

Deleuze, G. (1995) [1990]. Conversaciones 1972-1990. Valencia: Pre-Textos.

Deleuze, G., y Guattari, F. (1997) [1980]. Mil mesetas. Capitalismo y esquizofrenia II. Valencia: Pre-textos.

Delgado, M. (1999). El animal público. Hacia una antropología de los espacios urbanos. Barcelona: Anagrama.

Delgado, M. (2007). Sociedades movedizas. Pasos hacia una antropología de las calles. Barcelona: Anagrama.

Desjarlais, R. (1997). Shelter blues: sanity and selfhood among the homeless. Philadelphia: University of Pennsylvania Press.

Días Duarte, L. F., y Campos Gomes, E. de (2008). Três famílias. Identidade $e$ trajetórias transgeracionais nas classes populares. Río de Janeiro: Editorial FGV.
Flusser, V. (1994) [1991]. Los gestos. Fenomenología y comunicación. Barcelona: Herder.

Foucault, M. (1995) [1988]. Tecnologías del yo. Y otros textos afines. Barcelona: Paidós.

García Vargas, A., y Román Velázquez, P. (2011). Latin American cultural studies: unique texts, ordinary cities. Westminster Papers in Communication and Culture, 8(1), 131-153. Recuperado de https://www.westminster.ac.uk/__data/assets/pdf_ file/0017/93230/006WPCC-Vol8-No1Vargas-and-Velazquez.pdf

Geertz, C. (1996) [1973]. La interpretación de las culturas. Barcelona: Gedisa.

Goffman, E. (2004) [1959]. La presentación de la persona en la vida cotidiana. Buenos Aires: Amorrortu.

Guattari, F. (2000) [1989]. Cartografías esquizoanalíticas. Buenos Aires: Manantial.

Heidegger, M. (1994) [1954/1951]. Construir, habitar, pensar. En M. Heidegger. Conferencias y artículos. Barcelona: Serbal.

Heller, A. (1995). Where are we at home? Thesis Eleven, 41, 1-18.

Herzfeld, M. (2004). Cultural intimacy. Social poetics in the Nation-State. (2. ${ }^{\text {a }}$ ed.). Londres-Nueva York: Routledge.

Ingold, T. (2007). Lines. A brief history. Londres-Nueva York: Routledge.

Ingold, T. (2012). El diseño de ambientes para la vida. En T. Ingold. Ambientes para la vida. Conversaciones sobre hu- 
manidad, conocimiento y antropología. Montevideo: SCEAM-Udelar-Trilce.

Jacobs, J. M. (2004). Too many houses for a home. Narrating the house in the Chinese diaspora. En S. Cairns (Ed.), Drifting: architecture and migrancy (164-183). Londres-Nueva York: Routledge.

Jóhannesdóttir, G. (2010). Landscape and aesthetic values: not only in the eye of beholder. En K. Benediktsson, y K. A. Lund. Conversation with landscape. Farnham, Surrey: Ashgate.

King, P. (2008). In dwelling: implacability, exclusion and acceptance. Aldershot: Ashgate.

Latour, B. Yaneva, A. (2008). 'Give me a gun and I will make all buildings move': an ANT's view of architecture. En R. Geiser (Ed.), Exploration in architecture: teaching, design, research. Basel: Birkhéiuser.

Lotman, I. (2000) [1987]. La arquitectura en el contexto de la cultura. En I. Lotman. La semiosfera III. Semiótica de las artes y la cultura. Madrid: Cátedra.

Miller, D. (2008). The comfort of things. Cambridge: Polity Press.

Morduchowicz, R. (2008). La relación de los jóvenes y las pantallas. En R. Morduchowicz (Coord.), Los jóvenes y las pantallas. Nuevas formas de socialización. Buenos Aires: Gedisa.

Norberg-Schulz, Ch. (1984) [1979]. Genius loci: Towards a phenomenology of architecture. Nueva York: Rizzoli.

Olivera Chirimini, T. (2005). Expresiones culturales de los afro-riopla- tenses. Memoria del Simposio "La ruta del esclavo en el Río de la Plata: su historia y sus consecuencias". Montevideo: Unesco.

Oro, A. P., y Scuro, J. (2013). El aporte de Renzo Pi Hugarte sobre la transnacionalización religiosa entre Brasil y Uruguay. Anuario de Antropología Social y Cultural en Uruguay, 11, 23-36.

Perrot, M. (2011) [2009]. Historia de las alcobas. México: Fondo de Cultura Económica-Siruela.

Pezeu-Massabuau, J. (1988) [1983]. La vivienda como espacio social. México: Fondo de Cultura Económica.

Pezeu-Massabuau, J. (2012) [2004]. A philosophy of discomfort. Londres: Reaktion Books.

Poder Legislativo de la ROU. (24 de octubre de 2011). Ley 18.829. Plan Nacional de Integración SocioHabitacional "Juntos". Recuperado de http://www0.parlamento.gub.uy /leyes/AccesoTextoLey.asp?Ley= 18829\&Anchor=

Rincón, O. (2006). Narrativas mediáticas. O cómo se cuenta la sociedad del entretenimiento. Barcelona: Gedisa.

Segalen, M. (1996) [1986]. Historical anthropology of the family. Cambridge: Cambridge University Press.

Strathern, M. (1991) [1987]. Fuera de contexto. Las ficciones persuasivas de la antropología. En C. Reynoso (Comp.), El surgimiento de la antropología posmoderna. México: Gedisa. 